\title{
Towards High-Repetition-Rate Fast Neutron Sources Using Novel Enabling Technologies
}

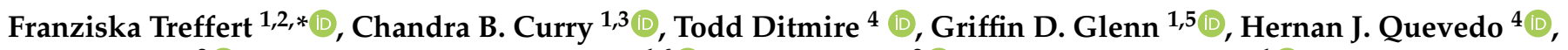

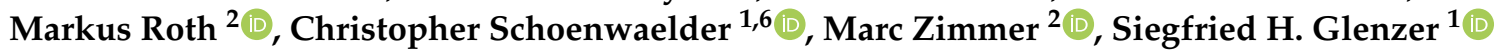 \\ and Maxence Gauthier ${ }^{1}$ (])
}

1 SLAC National Accelerator Laboratory, Menlo Park, CA 94025, USA; ccurry@slac.stanford.edu (C.B.C.); gdglenn@slac.stanford.edu (G.D.G.); schchris@slac.stanford.edu (C.S.); glenzer@slac.stanford.edu (S.H.G.); gauthier@slac.stanford.edu (M.G.)

2 Institut für Kernphysik, Technische Universität Darmstadt, 64289 Darmstadt, Germany; markus.roth@physik.tu-darmstadt.de (M.R.); m.zimmer@gsi.de (M.Z.)

3 Department of Electrical and Computer Engineering, University of Alberta, Edmonton, AB T6G 1H9, Canada

4 CHEDS, The University of Texas at Austin, Austin, TX 78712, USA; tditmire@physics.utexas.edu (T.D.); hjquevedo@utexas.edu (H.J.Q.)

5 Applied Physics Department, Stanford University, Stanford, CA 94305, USA

6 ECAP, Friedrich-Alexander Universität Erlangen-Nürnberg, 91058 Erlangen, Germany

* Correspondence: treffert@slac.stanford.edu

check for

updates

Citation: Treffert, F.; Curry, C.B.; Ditmire, T.; Glenn, G.D.; Quevedo, H.J.; Roth, M.; Schoenwaelder, C.; Zimmer, M.; Glenzer, S.H.; Gauthier, M. Towards High-Repetition-Rate Fast Neutron Sources Using Novel Enabling Technologies. Instruments 2021, 5, 38. https://doi.org/10.3390/ instruments5040038

Academic Editor: Antonio Ereditato

Received: 9 October 2021

Accepted: 29 November 2021

Published: 3 December 2021

Publisher's Note: MDPI stays neutral with regard to jurisdictional claims in published maps and institutional affiliations.

Copyright: (c) 2021 by the authors. Licensee MDPI, Basel, Switzerland. This article is an open access article distributed under the terms and conditions of the Creative Commons Attribution (CC BY) license (https:// creativecommons.org/licenses/by/ $4.0 /)$.

\begin{abstract}
High-flux, high-repetition-rate neutron sources are of interest in studying neutron-induced damage processes in materials relevant to fusion, ultimately guiding designs for future fusion reactors. Existing and upcoming petawatt laser systems show great potential to fulfill this need. Here, we present a platform for producing laser-driven neutron beams based on a high-repetition-rate cryogenic liquid jet target and an adaptable stacked lithium and beryllium converter. Selected ion and neutron diagnostics enable monitoring of the key parameters of both beams. A first single-shot proof-of-principle experiment successfully implemented the presented platform at the Texas Petawatt Laser facility, achieving efficient generation of a forward-directed neutron beam. This work lays the foundation for future high-repetition-rate experiments towards pulsed, high-flux, fast neutron sources for radiation-induced effect studies relevant for fusion science and applications that require neutron beams with short pulse duration.
\end{abstract}

Keywords: high power lasers; ultra-intense laser; high repetition rate; cryogenic liquids; liquid jets; plasma physics; ion acceleration; neutron source

\section{Introduction}

Neutron beams are a versatile, sensitive probe of material properties due to their interactions with the target atom through the strong force rather than the electromagnetic force, unlike X-rays and charged particles. Complementary measurements to X-ray probing using neutron beams can therefore resolve properties that are challenging to observe otherwise. Consequently, directional, high-flux neutron beams are of high interest for applications including fusion energy science [1], fundamental physics research [2], materials science [3], homeland security [4], and medicine [5]. High-energy-density physics is a field that can greatly benefit from neutron beams with short pulse duration and high flux. Due to the violent nature and abundance of magnetic and electric fields under such conditions, neutron probing offers a new and unique way to measure material structure or ion temperature and velocity in dense plasmas [2,6]. More recently, neutron sources have gained significance as a key tool in the study of radiation-induced effects in fusion science; in particular, damage cascades or neutron-induced transmutations relevant for fusion reactor materials and astrophysical scenarios (e.g., s- and r-processes) [7]. These studies will significantly advance designs and construction of a fusion pilot plant such as 
the internationally-supported ITER project $[8,9]$ and guide the development of a DEMO fusion reactor, pursued by multiple countries $[10,11]$. The success of these projects is of high importance, as it will drive a fundamental revolution in the supply and consumption of power, while having a positive impact on the Earth [12].

At present, high-flux neutron beams are routinely produced by nuclear reactors or spallation sources, in which neutrons are generated via nuclear fission in a reactor core or in spallation reactions induced by a $\sim \mathrm{GeV}$ proton beam impinging on a high- $\mathrm{Z}$ target. Table 1 summarizes current neutron source specifications including those of lasers as alternative drivers. Reactors and spallation sources attain high average neutron fluxes of up to $10^{15}$ neutrons $/\left(\mathrm{cm}^{2} \mathrm{~s}\right)$ but lack flexibility for probing and suffer from their relatively long pulse duration (hundreds of ns or greater) $[13,14]$, which prevents probing of quickly evolving systems with sufficient resolution.

Table 1. Overview of the characteristics of presently available neutron sources. (adapted from [7]).

\begin{tabular}{lcccc}
\hline \multicolumn{1}{c}{ Neutron Source } & Peak Flux $\left(\frac{\mathbf{n}}{\mathbf{c m}^{\mathbf{2}} \mathbf{s}}\right)$ & Average flux $\left(\frac{\mathbf{n}}{\mathbf{c m}^{\mathbf{2}} \mathbf{s}}\right)$ & Bunch Duration & Repetition Rate (Hz) \\
\hline Reactor [15] & $\sim 10^{15}$ & $\sim 10^{15}$ & continuous & continuous \\
Spallation [15] & $\sim 10^{16}$ & $\sim 10^{12}$ & $\sim 1 \mu \mathrm{s}$ & 60 \\
Current lasers [16-18] & $10^{18}-10^{19}$ & $5 \times 10^{5}-5 \times 10^{6}$ & $\sim 1 \mathrm{~ns}$ & $5 \times 10^{-4}$ \\
Laser fusion (ICF) [19] & $>10^{27}$ & $>10^{11}$ & $\sim 100 \mathrm{ps}$ & $4 \times 10^{-6}$ \\
\hline
\end{tabular}

Recently, high-power laser systems have demonstrated their utility as drivers of highflux neutron sources following two approaches. In the first approach, inertial confinement fusion (ICF), neutrons are produced by heating a target to temperatures exceeding tens of $\mathrm{keV}$ while simultaneously compressing it to pressures in the hundreds of Mbar $[20,21]$. Long-pulse (ns-10 ps), high-power, single shot lasers (1-5 shots/day) at the National Ignition Facility (NIF) and OMEGA achieve isotropic neutron emission on the order of $10^{26}$ neutrons $/\left(\mathrm{cm}^{2} \mathrm{~s}\right)$ via fusion reactions in a single laser-heated target through direct or indirect drive of a shock wave into the target [22,23]. Alternatively, short-pulse lasers can directly heat and compress a target with the fusion volume being proportional to the $\mu \mathrm{m}$-scale laser plasma interaction volume. Consequently, lower neutron yields on the order of $10^{20}$ neutrons $/\left(\mathrm{cm}^{2} \mathrm{~s}\right)$ have been demonstrated using different lasers and target types [24-27].

The second, more-common approach relies on a pitcher-catcher geometry consisting of two targets separated by up to $5 \mathrm{~cm}$. The pitcher target (pitcher) is irradiated by a short (sub ps) laser pulse and emits an ion beam. A catcher target (catcher/converter) captures the ion beam close to the pitcher, and neutrons are created through nuclear reactions between the ions and catcher atoms $[2,28,29]$. These sources have demonstrated record peak flux of up to $10^{19}$ neutrons $/\left(\mathrm{cm}^{2} \mathrm{~s}\right)$ but are still limited to repetition-rates of $\sim 1$ shot/hour by laser capabilities and the target refresh times, resulting in low average flux [30].

The inherently short duration of laser-driven ion beams produces neutron bunches with pulse durations on the order of a nanosecond, giving such neutron sources the potential to become unique probes of fast-evolving processes. Advances in laser technology, culminating in the recent commissioning and successful operation of multiple high-repetition-rate petawatt lasers, promise to overcome repetition rate restrictions [31]. Combined with recent significant progress in delivery of continuous, debris-free targets [32-34], shot rates of $1 \mathrm{~Hz}$ or greater are achievable. Ion beam brightness and cut-off energies (and consequently neutron flux) are observed to scale with laser energy [35-38]; additional laser and highrepetition-rate target development therefore promises to further increase neutron fluxes to levels exceeding $10^{19}$ neutrons $/\left(\mathrm{cm}^{2} \mathrm{~s}\right)$.

For the purpose of systematically studying ideal regimes for efficient laser driven neutron generation, we have developed a high-repetition-rate compatible platform using 
a pitcher-catcher setup that is adaptable to different experimental environments. While this type of setup has been successfully used for neutron generation at a single shot over the past decade [16,39-43], our platform takes advantage of a novel high-velocity ( $>100 \mathrm{~m} / \mathrm{s}$ ) planar cryogenic liquid deuterium jet [44] (pitcher) and an adaptable converter to generate high-flux, directed neutron beams at high repetition rate. In the following sections, we thoroughly discuss the setup and the individual components. Finally, we present an outlook for this platform as a future high-flux, high-repetition-rate, laser-driven neutron source co-located with state-of-the-art laser and X-ray capabilities to enable unique probing of materials relevant to fusion.

\section{Platform Setup}

Essential to the setup are the short-pulse, high-repetition-rate petawatt (PW) laser, the cryogenic liquid deuterium pitcher for ion acceleration, and the catcher for ion-to-neutron conversion. The combination of the high-shot-rate laser with the quickly replenishing target allows for operation at rates exceeding $1 \mathrm{~Hz}$. A schematic of the setup is shown in Figure 1. It was designed to maximize the flux delivered in directional, high-energy neutron beams. First, experiments using this platform were successfully conducted at the single shot Texas Petawatt Laser facility [45]; see Section 7.

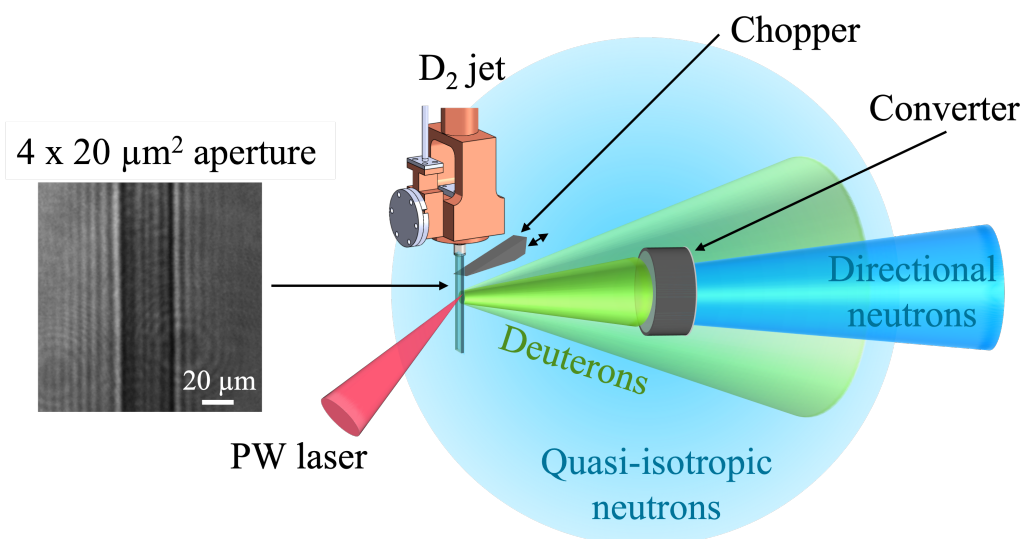

Figure 1. The platform setup consists of a petawatt laser, the cryogenic liquid $\mathrm{D}_{2}$ jet target for deuteron acceleration, and the converter for neutron production. A shadowgraphy image of the planar cryogenic deuterium jet target is shown in the inset. The neutron beam has both a quasiisotropic and a directional component.

A petawatt laser pulse is focused onto a sheet of cryogenically cooled deuterium, which is formed in the target chamber using a $4 \times 20 \mu^{2}$ aperture nozzle, at an incidence angle of $45^{\circ}$. Upon interaction of the PW laser with the jet, deuterium ions are accelerated in the target normal direction from the target's rear side. Crucial laser parameters for efficient ion generation include laser intensities on target exceeding $10^{18} \mathrm{~W} / \mathrm{cm}^{2}$ and a laser-pulse temporal contrast exceeding $10^{10}\left(10^{8}\right)$ in the multiple (sub)-picosecond window before arrival of the main laser pulse [46-48]. While some lasers are able to inherently achieve such high pulse contrast [49], other laser systems rely on plasma mirrors compatible with high repetition rates $[50,51]$. These optics transition from nonreflective to reflective at an ultrafast timescale through ionization and formation of an overcritical surface plasma upon high-intensity laser irradiation. Consequently, prepulses or the pedestal of such a laser pulse are only partially reflected while the main pulse is mostly reflected, enhancing the overall pulse contrast.

Neutrons are generated when the pure deuteron beam impinges on the converter, which is placed along the target normal direction in the cone of the expanding deuteron beam. Depending on positioning of the converter relative to the catcher, a subset of the deuteron beam is fully captured by the converter, as shown by the darker shaded 
green cone in Figure 1. The neutrons produced within the converter are emitted both quasi-isotropically and directionally.

\section{High-Repetition-Rate Cryogenic Deuterium Jet Target}

The pitcher is a planar, micron-scale, cryogenically-cooled, and fast-replenishing deuterium jet $[34,44,52]$. Liquid deuterium is continuously injected from a small reservoir into the vacuum chamber through the nozzle, then forms a solid sheet through evaporative cooling. Its stability is influenced by the jet backing pressure and injection temperature. Recent optimization of the jet operation has significantly improved the jet stability and consequently the shot-to-shot ion beam reproducibility; for further details, see [34]. As a result of the target formation directly inside the vacuum chamber using ultra-high purity gas, cryogenic jets are contaminant-free, single-species targets. A liquid jet catcher assembly located a few millimeters below the laser-target interaction point catches and evacuates the majority of the cryogenic deuterium before vaporization to ensure a sufficient vacuum level $\left(\leq 10^{-3} \mathrm{mbar}\right)$, improving jet stability. Previous experiments using the cryogenic jet at high-power-laser facilities have shown damage accumulation and destruction of the nozzle depending on laser power and shooting distance. To mitigate this problem, the direct line of sight from the interaction point to the jet nozzle is blocked upon laser-target interaction using a synchronized mechanical chopper system; see Figure 1 for its placement relative to the nozzle and laser target interaction point. After the laser interaction, the target residue vaporizes and is evacuated through the pumping system without accumulating on optics or chamber components, making this target inherently debris-free. Under stable operating conditions in a laminar flow regime, the jitter increases linearly with the distance from the nozzle [44]. Its position stability was previously characterized at a distance of $10 \mathrm{~mm}$ from the aperture to range from 3 to $12 \mu \mathrm{m}$ [53].

\section{Ion Beam Generation}

Ion beams accelerated using cryogenic jet targets exhibit beam parameters comparable to those of the Target Normal Sheath Acceleration (TNSA) regime [54-56]. Their main features are ion purity as well as a high-flux, target-normal directed component with small (a few to tens of msr) solid angle and a semi-Maxwellian ion energy distribution [53]. The angular distribution of the TNSA-like accelerated ion beam is conical and energydependent, with decreasing solid angles for increasing ion energies [57]. Due to the limited mass of the cryogenic jet target, a low-energy azimuthal component is added to this emission profile [58]. Previous work utilizing the 100 TW Draco laser system at HZDR (Dresden, Germany) demonstrated efficient and stable ion generation from cryogenic jets at $1 \mathrm{~Hz}[53,59]$.

\section{Deuteron Beam Diagnostics}

The laser-accelerated deuteron beam is characterized by the total ion yield, the energy distribution and cut-off energy, and the spatial distribution. In the presented setup, these characteristics are measured by Thomson parabola (TP) spectrometer detectors and an ion imager; see Figure 2. Continuous monitoring of the deuteron beam parameters enables neutron yield predictions and benchmarking of neutron generation simulations. This way, dominant neutron production channels can be identified, and the conversion efficiency from deuterons to neutrons can be estimated.

Three Thomson parabolas are set up at different angles with respect to the target normal direction. A TP in the target normal direction measures the ion beam spectrum and its high-energy directional component that will be incident on the neutron converter. At $30^{\circ}$ from target normal, the second TP measures the ion beam at the transition between the directional and the non-directional component. Monitoring the change in the ion cut-off energy across multiple shots at this location also helps maintain consistent target alignment. A third TP at $120^{\circ}$ from target normal measures the non-directional component of the ion beam. The ion imager is positioned close to the line of sight of the target normal TP, at 
$10^{\circ}$ from the target normal direction and a distance of around $5 \mathrm{~cm}$ from the target, to capture the majority of the directional ion beam. This enables cross-calibration of TP and imager data.

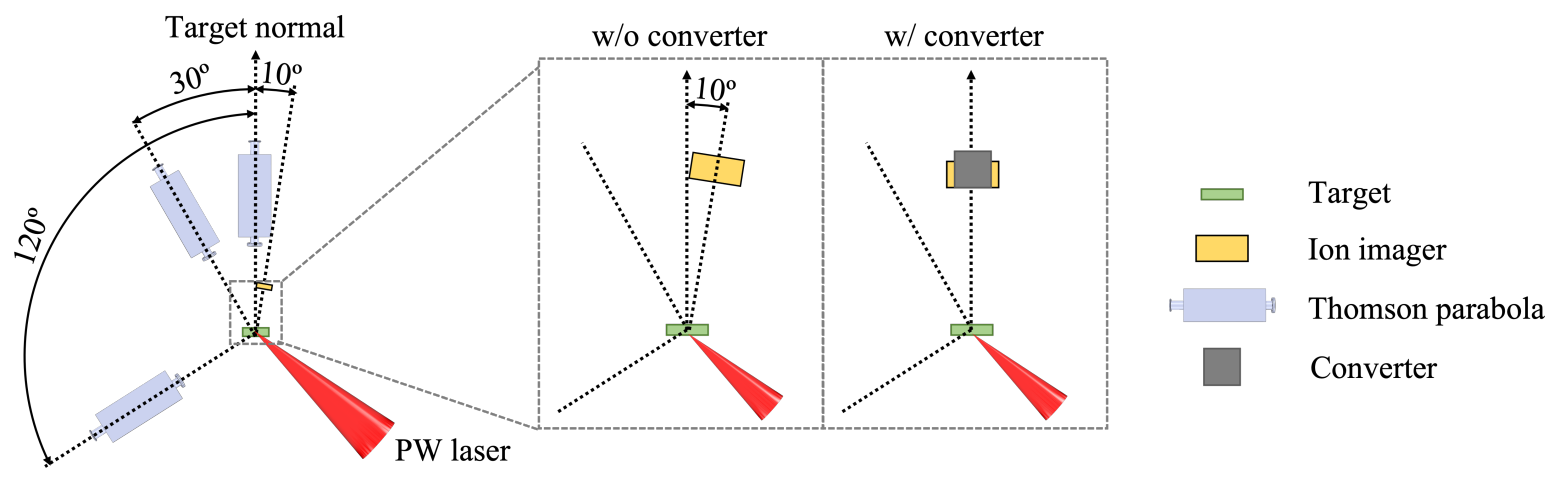

Figure 2. Ion beam diagnostics, three Thomson parabolas and an ion imager, placed around the converter during neutron generation, are set up at various angles from the target normal direction.

After completion of the initial characterization of the accelerated ion beam and the implementation of the converter, the diagnostics presented here monitor the ion acceleration efficiency and performance by comparing beam parameters to previously obtained references. To make the setup displayed in Figure 2 compatible with the converter implemented in the target normal direction, a small hole $(\sim 0.5 \mathrm{~mm})$ can be drilled along the axis of the converter to enable the continued measurement of the ion spectrum. The ion imager is placed around the converter to track the lower-energy part of the directional ion beam.

\subsection{Thomson Parabola}

The energy spectrum and flux of a laser-driven ion beam is commonly measured using Thomson parabola spectrometers. These devices employ parallel or antiparallel electric and magnetic fields to disperse ions according to their charge-to-mass ratios and energies. TPs sample a small solid angle, typically a few $\mu$ sr. Since the ion spatial profile of TNSA-like beams is generally smooth, two or more TPs are usually positioned at various angles to the target normal direction to diagnose the ion beam characteristics as a function of emission angle. To enhance the understanding of the ion beam energy distribution as a function of opening angle, recent efforts have investigated the feasibility of multi-pinhole Thomson parabolas [60].

Presently, many TPs still rely on imaging plates (IPs) to detect the deflected ion beam [61]. However, IPs must be read out using a nonconfocal phosphor scanner, such as the Typhoon FLA 7000. As such, they are not suitable for high-repetition-rate operation. Instead, detector units consisting of a combination of a scintillator or microchannel plate $(\mathrm{MCP})$ with a scintillator and a fast, gated camera are preferred, which are limited in repetition-rate by the dead time of the detector unit and the frame rate of the camera used. Each individual combination of scintillator/MCP and camera requires a separate calibration to be able to infer the number of incident ions from the recorded pixel value.

\subsection{Ion Imager}

Complementary energy-resolved spatial profiles are collected using an ion imager to fully characterize the accelerated deuteron beam. The commonly employed single-shot radiochromic film (RCF) stack is based on radiation-sensitive dye. It allows for extraction of incident particle numbers based on optical density, which is obtained by scanning the films post-exposure while resolving the energy through stacking of multiple films [62-64]. To overcome the single-shot limitations of RCF stack detectors, scintillator-based ion imagers are under active development in order to provide energy-resolved ion beam spatial profiles at high repetition rates. These efforts focus on two different approaches. The first method 
relies on energy resolution through stacking of thin scintillators, similar to the RCF stack. While one technique uses different types of scintillators emitting different wavelengths imaged from the stack rear side $[65,66]$, another achieves energy resolution by stacking the same type of scintillator at an angle and imaging the individual scintillators from the side [67]. The second method only uses one scintillator in combination with an absorber mesh, achieving energy resolution by periodically varying the thickness of the absorber on the mesh [68-70]. The spatial resolution of such setups is usually limited by the absorber mesh pixel size, the ion transverse scattering, and the grain size and lateral photon spread of the scintillator. Recent efforts have investigated the improvement of the spatial resolution of the scintillators through division of the bulk material into individual scintillators with smaller volume (pixelation) [71].

\section{Neutron Generation in Pitcher-Catcher Configuration}

In our approach, neutron beams are generated when an intense ion beam interacts with a converter material. The converter is designed to optimize neutron production processes based on their cross section for different converter materials.

\subsection{Nuclear Reaction Channels}

Neutrons are produced in a converter material through three different mechanisms: elastic breakup, complete fusion (compound formation followed by neutron emission), and incomplete fusion (inelastic breakup or deuteron stripping) [72-74]. While complete fusion reactions occur for any type of incident ion, elastic breakup and incomplete fusion are interaction paths unique to deuterons.

Elastic breakup occurs in the vicinity of a converter atom, which does not partake in the reaction. Deuterons dissociate in the Coulomb potential of converter atoms, thus producing a proton and a neutron. The generated neutron beam has a continuous energy spectrum similar to that of the incoming ion beam and is forward-directed due to conservation of momentum.

During complete fusion, the deuteron and the target atom form a short-lived compound state that then decays to a more stable atom through emission of a neutron either before or after equilibration. The quasi-isotropically emitted neutrons are quasimonoenergetic for pre-equilibrium emission and have an evaporation-like spectrum for post-equilibrium emission.

Incomplete fusion is a hybrid of elastic breakup and complete fusion. When elastic breakup occurs close enough to the converter atom, the liberated proton is captured by the target atom, also referred to as deuteron stripping. If the resulting intermediate compound state is unstable, it can decay via emission of another neutron. Consequently, neutrons produced by incomplete fusion have a directed component from deuteron stripping and a quasi-isotropic component from complete fusion, with an energy spectrum given by the sum of the monoenergetic and continuous spectra produced from the two underlying processes.

Of these three mechanisms, elastic breakup and incomplete fusion are often preferred for laser-driven neutron beam applications due to their higher reaction cross sections and the directionality of the neutron beam.

\subsection{Converter Design}

The final converter design for a maximized overall neutron yield is derived by considering three parameters in the following order: (1) its shape and transverse width, (2) the pitcher-to-converter distance, and (3) the converter composition and thickness.

The ideal shape to maximize conversion efficiency of a TNSA-like deuteron beam to neutrons is dictated by the cone-like emission of the ion beam. Consequently, a cone-shaped converter design would be ideal, but can complicate implementation of the converter itself or other necessary diagnostics. Therefore, we choose a cylindrical converter, with a 
transverse width of 1 inch $(2.54 \mathrm{~cm})$, to match the circular cross section of the cone-like spatial emission profile of the ion beam.

In order to determine the distance between pitcher and converter, the opening angle of the ion beam $\left(\sim 33^{\circ}\right.$ half angle) has to be taken into account. A short distance between pitcher and catcher is preferred to be able to capture the majority of the accelerated deuterons. The closer the converter is to the pitcher, the smaller the spatial cross section of the accelerated ion beam and the source size of the neutron beam. Moreover, due to the energy spread (chirp) of the ion beam, the pulse durations of the ion beam and resulting neutron beam increase with distance.

On the other hand, the possible damage to the converter caused by laser light transmitted through or past the pitcher jet target has to be assessed. The potential for damage is primarily limited by rotating the target by $45^{\circ}$ relative to the laser forward direction. However, due to the large opening angle of the emitted ion beam, there is an overlap of the transmitted laser light cone with the deuteron beam. Figure 3 illustrates this issue for an $f / 2$ final focusing optic. The intensity of the transmitted laser light stays beyond or near the damage threshold of most materials, typically on the order of $10^{11}-10^{13} \mathrm{~W} / \mathrm{cm}^{2}$, for several $\mathrm{cm}$ behind the target. Assuming an $f / 2$ focusing optic and a laser energy on the target of 10-100 J, a distance on the order of tens of $\mathrm{cm}$ is necessary.

A compromise between maximizing the total number of ions captured by the converter and minimizing the potential damage by laser light can be found by placing the converter close to the pitcher and still outside the transmitted laser light. A blast shield that will deflect away any incident scattered laser light is added to the front of the converter. It consists of a No. 1.5 borosilicate glass microscope cover slip (170-250 $\mu \mathrm{m}$ thick) with a $40 \mathrm{~nm}$ thick aluminium coating. This allows the distance between pitcher and converter to be reduced to around $5 \mathrm{~cm}$, depending on the laser intensity on target and the focal length of the final focusing optic. At this distance, the covered half opening angle is $14^{\circ}$, fully capturing deuteron energies above approximately $30 \mathrm{MeV}$. Ions with lower energy will not all be captured by the converter and will produce neutrons upon interacting with either the chamber wall or other components in the target chamber.

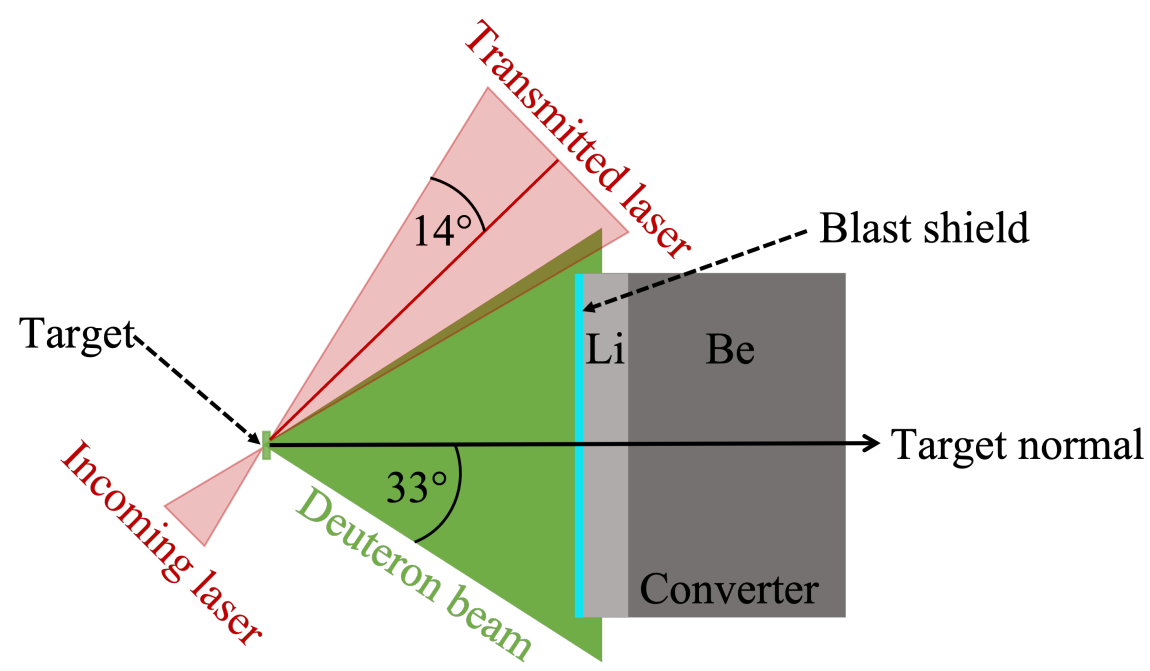

Figure 3. Top view of the setup (target size not to scale). The converter is placed in the target normal direction to capture the ion beam but outside the transmitted laser cone $(f / 2)$ to avoid damages.

Low-Z materials such as lithium or beryllium are ideal as converters for deuterondriven neutron generation $[16,28,75,76]$. The converter composition is determined by considering deuteron stripping $(\mathrm{d}, \mathrm{n})$, deuteron elastic breakup $(\mathrm{d}, \mathrm{n}+\mathrm{p})$, and fusion nuclear reactions $(\mathrm{d}, \mathrm{n}+\mathrm{x})$, where $\mathrm{x}$ can be $\alpha, \mathrm{n}$, or $\mathrm{t}$.

The deuteron elastic breakup cross section has not been studied in great detail in the energy ranges of interest for laser-driven neutron generation, but it is on the order of 
100s of mb for energies above $10 \mathrm{MeV}$ for both lithium and beryllium [77,78]. Neutron generation cross sections of fusion reaction channels, such as $(\mathrm{d}, 2 \mathrm{n})$ and $(\mathrm{d}, \mathrm{n}+\alpha)$, for lithium and beryllium attain maximum values of tens of $\mathrm{mb}[79,80]$. The cross sections of the most important neutron-generating interactions of deuterium with lithium and beryllium are displayed in Figure 4. Interaction cross sections for deuterium with beryllium, such as $(\mathrm{d}, \mathrm{n}+\mathrm{t})$, are not shown in this plot as they are lower by one order of magnitude compared to the displayed cross section and are thus neglected during further considerations. Experimentally measured interaction cross sections are depicted by crosses in the plot, confirming simulated neutron production cross sections. Lithium shows four different reaction channels that are dominant in different energy ranges. The ${ }^{7} \mathrm{Li}(\mathrm{d}, \mathrm{n})$ (stripping) reaction shows a high reaction cross section for energies ranging from $\sim 100 \mathrm{keV}$ to $\sim 10 \mathrm{MeV}$ [81]. For higher energies, deuteron breakup $\left({ }^{7} \operatorname{Li}(\mathrm{d}, \mathrm{n}+\mathrm{p})\right)$ becomes significant due to a higher reaction cross section value with a maximum of $\sim 150 \mathrm{mb}$ at around $15 \mathrm{MeV}$ [79]. The two other neutron production channels exhibit lower cross section values and have not been predicted for energies beyond $20-30 \mathrm{MeV}$ due to a lack of experimental data [79]. The neutron generation cross section for beryllium exhibits a similar trend, where deuteron stripping dominates for lower energies, while deuteron breakup becomes significant for higher energies. Contrary to lithium, the breakup reaction gains significance at energies above $20 \mathrm{MeV}$. In the $10-20 \mathrm{MeV}$ energy range, the ${ }^{9} \mathrm{Be}(\mathrm{d}, \mathrm{n}+\alpha)$ reaction becomes dominant over deuteron stripping or breakup.
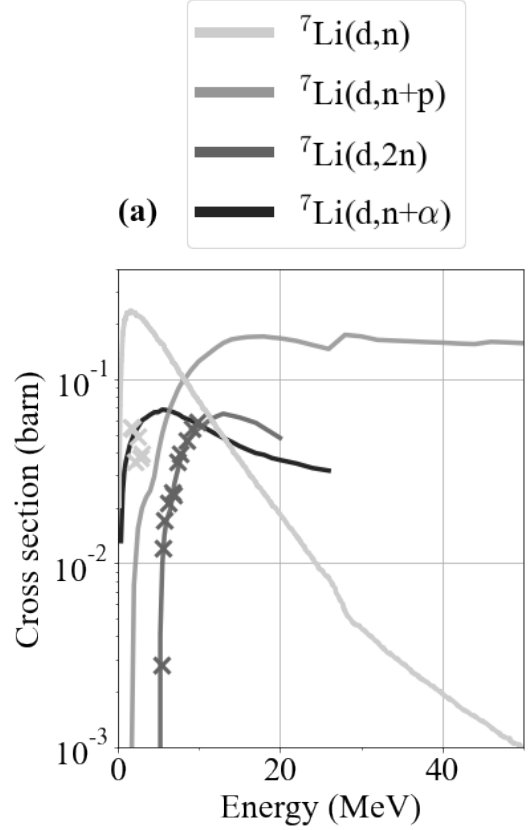
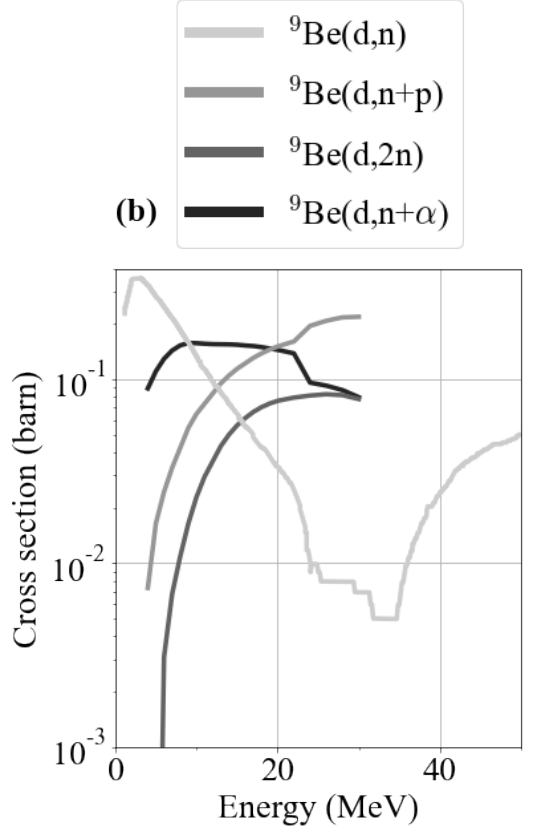

(c)
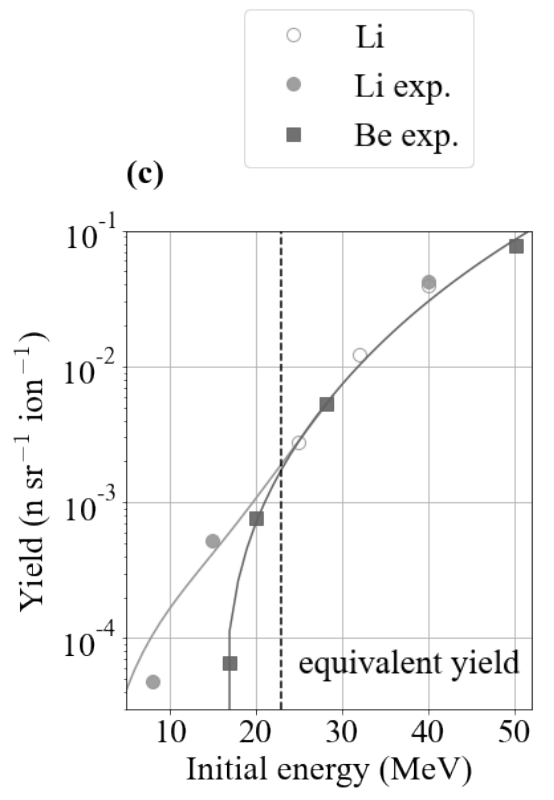

Figure 4. (a) Simulated neutron production cross sections (solid lines) [79-81] and corresponding experimental values (crosses) for lithium [82-84], (b) simulated neutron production cross sections for beryllium [79-81,85] and (c) experimental neutron yields (full circles) for lithium $(8,12$, and $15 \mathrm{MeV}$ from [86], $40 \mathrm{MeV}$ from [87]) and for beryllium (squares) from [88] measured with a monoenergetic deuteron beam produced by an accelerator impinging on a thick converter target as well as simulation studies (empty circles) using Monte Carlo codes $[89,90]$. The plotted lines are a guide to the eye for the two different materials. To the right of the dashed line lithium and beryllium show equivalent neutron yield for incident deuterons with the same energy. (adapted from [76]).

Considering the continuous ion spectra typically generated during TNSA-like ion acceleration, a roughly constant neutron generation cross section across all ion energies is important to increase the conversion efficiency. This makes lithium a much more efficient converter material for lower incident ion energies and will yield higher neutron fluxes for the low energy tail of TNSA-like ion beams compared to beryllium. Experimental results and simulations for the overall neutron yield using monoenergetic ion beams incident 
on these two materials confirm this argument as shown in Figure 4c. Here, the neutron yield per incident ion per steradian is plotted for lithium and beryllium as a function of the energy of an incident monoenergetic deuteron beam. While the neutron yield for beryllium at incident energies below $23 \mathrm{MeV}$ drops quickly, the neutron yield for lithium drops more gradually with a decreasing incident deuteron energy. Above $23 \mathrm{MeV}$, as indicated by the dashed line, the yield for lithium or beryllium is almost identical.

Beryllium is chosen as the bulk material of the catcher due to a higher number of interaction channels for deuteron energies higher than $23 \mathrm{MeV}$, as seen in Figure $4 a, b$, leading to an overall higher neutron generation probability. Since the deuteron-to-neutron conversion efficiency for lithium is higher for lower energies, a $6 \mathrm{~mm}$ lithium disk is chosen to precede beryllium in a stacked converter design. For a detailed theoretical study of this design, see Ref. [91]. The maximum necessary thickness of the converter and the beryllium layer is estimated based on the range of deuteron ions with maximum cut-off energies measured in the experiment, which are calculated using stopping power tables provided by SRIM [92]. Following the calculation, the dimension of the beryllium layer can be adjusted using beryllium disks of different thicknesses. When determining the thickness of the beryllium layer, the relatively high neutron absorption cross section (above $100 \mathrm{mb}$ ) of beryllium compared to other neutron converter materials has to be taken into account. In order to minimize scattering or yield losses in the converter itself, the design is kept to its minimum thickness to ensure both efficient ion stopping and an unperturbed neutron beam. It has to be noted that the determination of transition between lithium and beryllium did not include a dedicated study of the neutron yield as a function of penetration depth and incident ion energy. For an optimized design, such a study is essential in order to maximize the conversion efficiency from deuterons to neutrons.

For maximized neutron yield, the traces of higher-energy deuterons are ideally centered on the axis of the converter. To date, few studies have investigated the possibility of tracking the ion beam within the converter. Techniques include wrapping the converter material with imaging plates, copper plates [93], or RCF in the converter [94]. Such tracking layers yield measurements of the ion beam flux and spatial distribution at certain depths within the converter corresponding to a specific ion energies. However, these techniques are limited to single-shot use due to read-out requirements. For a rep-rated diagnostic, a thin scintillator screen could be installed in front of the converter that is imaged by a camera and monitors the beam position relative to the converter body. Another option would be to machine a converter with an open slit cross section throughout. This will allow implementation of a thin scintillator layer at a certain depth, corresponding to higher ion energies. The scintillator signal can be monitored from the rear side of the converter.

\section{Neutron Beam Detection}

Understanding the underlying neutron production mechanisms and governing parameters requires a thorough characterization of emitted neutrons in terms of directionality, total flux, and energy distribution. For this purpose, a detector setup is designed using bubble and neutron time-of-flight (nTOF) detectors. Figure 5 shows the location of the bubble detectors (left) and nTOF detectors (right) in the laser plane.

An ensemble of bubble detectors measures the neutron numbers for a specific energy range and emission angle to provide insight into the spatial variation of neutron emission. The setup covers the full $360^{\circ}$ in the laser plane, with the majority of the detectors mounted on the target chamber outside wall at a distance $r_{T C}$ from the pitcher (Figure 5). To resolve the transition from the predicted high-yield directional component to the isotropic emission, bubble detectors are mounted closer together in the target normal direction and spaced out at larger angles. The assessment of the isotropic emission from the bubble detectors at large angles allows estimation of the contribution of the directed neutron beam to the overall yield. 

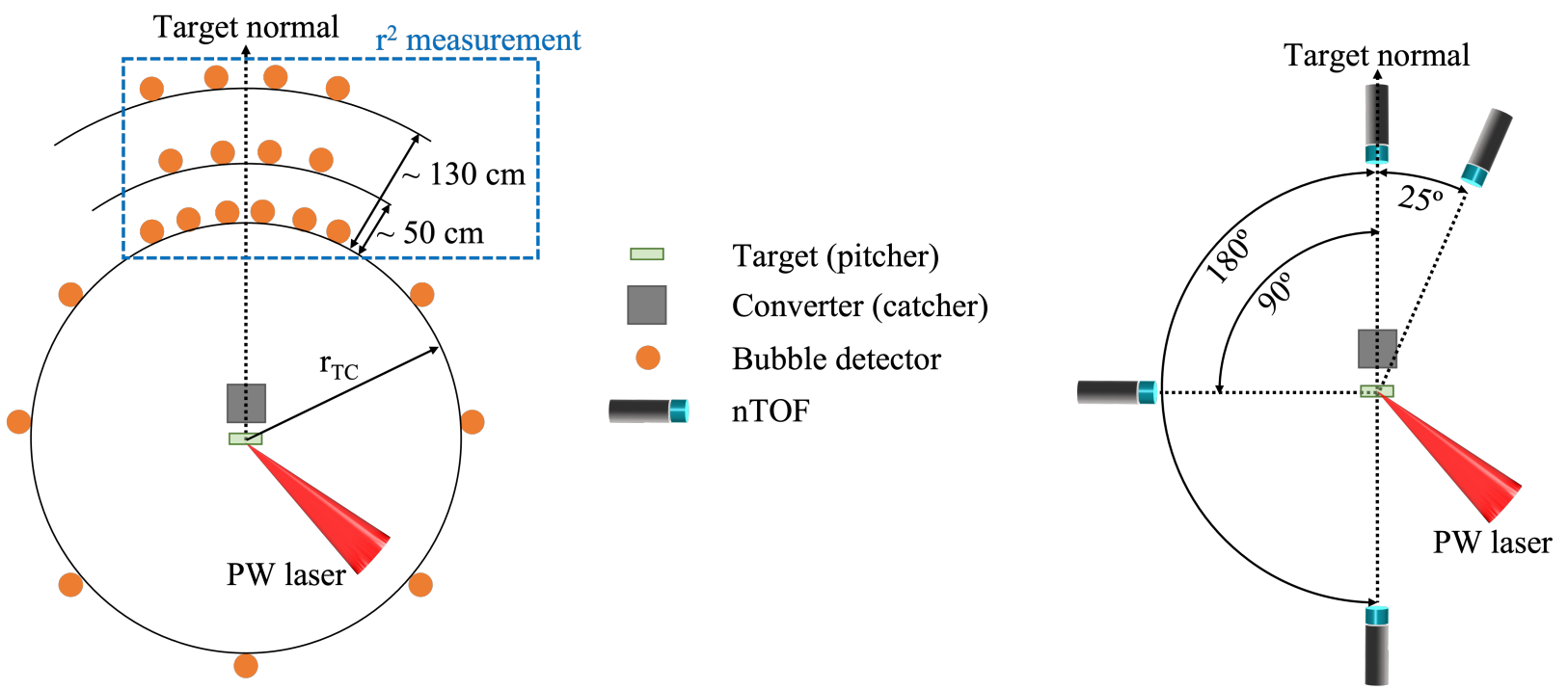

Figure 5. Setup for the neutron flux measurement in the laser plane using bubble detectors (left). The energy spectrum is measured using neutron time-of-flight detectors at selected angles (right).

The flux per solid angle, which can be compared to other detector measurements, is calculated assuming a neutron source location, typically the converter. However, depending on the distance between the pitcher and the converter and the emission profile of the ion beam, neutrons can be generated in other components within the target chamber or the chamber wall. Distinguishing between the different neutron sources and determining the main source location is especially important to determine the source size of the forwarddirected neutron beam and its opening angle and allows for more precise predictions of deuteron-to-neutron conversion efficiency. For this purpose, we developed a dedicated setup using bubble detectors in the target normal direction and laser plane at various distances $(0 \mathrm{~cm}, 50 \mathrm{~cm}$ and $130 \mathrm{~cm})$ from the target chamber wall; see blue dashed box in Figure 5 . The relative solid angle sampled by a bubble detector is proportional to the square of the distance $r$ from a neutron source. Thus, the measured neutron number per solid angle is directly sensitive to the relative placement of the detectors. Assuming a source location, the neutron numbers can be predicted at $50 \mathrm{~cm}$ and $130 \mathrm{~cm}$ from the chamber wall, using the $r^{2}$-scaling and the neutron numbers measured at the chamber wall. These predictions are then compared to the experimentally detected neutron numbers. If the numbers match within the margin of error given by the experimental values, the assumed source is the dominant source for neutron generation. The main uncertainty of this method is given by the inherent uncertainty in the response of the bubble detectors $(\sim 20 \%)$ [95], with a smaller contribution due to measurement uncertainties of the distance from detector to the assumed source location $(\sim 2 \%)$. The contribution of neutrons generated in different locations such as the chamber wall is minimized by placing the bubble detectors in the "shadow" of the converter. In this region, no deuterons will interact with the chamber wall directly adjacent to the bubble detectors. Comparing the neutron signal from these detectors to that obtained from detectors outside the converter shadow allows one to determine whether the overall dominant neutron source is the converter (as depicted in Figure 1) or the chamber wall.

While bubble detectors with different material compositions can be used to sample a portion of the energy spectrum as part of a bubble detector spectrometer [96], their sensitivity drops significantly for energies above $10 \mathrm{MeV}$. Therefore, neutron energy distributions are commonly measured by employing nTOF detectors at different angles. In this setup, four nTOF detectors are placed in target normal direction and at $25^{\circ}, 90^{\circ}$, and $180^{\circ}$ from target normal. 


\subsection{Bubble Detectors}

Neutron flux is commonly measured using bubble detectors [96], dosimetry detectors that are sensitive to a specific neutron energy range and insensitive to gamma radiation. These detectors rely on the expansion of superheated liquid droplets to visually detectable size upon energy deposition from incident neutrons [97,98]. The number of bubbles is proportional to the total deposited energy dose, given as a calibration of bubbles to mrem, which allows conversion to the number of incident neutrons. While the manufacturerstated calibration has been proven to differ from the actual response of the detector by up to $20 \%$ [99,100], those uncertainties can be mitigated by performing a separate calibration measurement with a neutron source of known flux. Currently, these single-shot diagnostics are either reset after each measurement or used to measure the average neutron yield accumulated over a series of laser shots. For precise neutron flux measurements at high repetition rates, this detector can easily be adapted, for example by monitoring the bubble count in the detector in real time over the course of a shot sequence, as bubble formation only takes a few milliseconds [101]. ${ }^{3} \mathrm{He}$-based or other proportionally counting dosimetry detectors are other high-repetition-rate alternatives [102,103].

\subsection{Neutron Time of Flight Detectors}

Measurement of the full neutron energy spectrum along a single line of sight is typically accomplished with nTOF detectors. These devices consist of a fast-decaying (a few ns) scintillator, typically organic plastic, coupled to a photomultiplier tube (PMT) for signal conversion and amplification. Unlike bubble detectors, nTOF detectors are sensitive to any kind of ionizing radiation, including gamma radiation produced during the interaction of the high-power laser with the pitcher. Non-ionizing radiation, such as neutron ratiation, is detected indirectly through creation of knock-on protons in the scintillator material. These knock-on protons transfer their energy to scintillator atoms and excite them to an unstable higher energy state that decays via emission of light. The PMT collects the light and converts it into an electric signal through the photoelectric effect and subsequently amplifies it. The electronic signal is recorded as a function of time using a fast sampling rate $(\geq 1 \mathrm{GHz})$ oscilloscope. The time of the initial laser-pitcher interaction $\left(t_{0}\right)$ is given by the gamma signal and its time of flight to the nTOF detector. After determination of $\mathrm{t}_{0}$, the neutron time-of-flight can be calculated for any data point along the signal. The energy of the neutrons incident on the detector is calculated taking into account the distance from the neutron source to the detector. The electronic read-out and fast decay time of the scintillator make these detectors naturally suited for high-repetition-rate operation.

Due to the direct detection of gamma radiation by the scintillator, nTOF detectors are more sensitive to gamma radiation than they are to indirectly detected neutrons. This oftentimes results in the saturation of the detector due to the incident gamma radiation. For directional neutron sources a clear temporal separation between the fast gamma and slower neutron signal (Figure 6) can be achieved for sufficiently large distances between detector and source. Laser-driven neutron beams exhibit quasi-directional to quasi-isotropic neutron emission, which results in neutron fluxes and detected TOF signals decreasing with the square of the distance between source and detector. Consequently, it is usually not possible to place the detector far enough away to achieve clear temporal separation between gamma and neutron signals, as the neutron signal level would drop below or close to the noise threshold. As a compromise, neutron detectors are typically placed $\sim 1-8 \mathrm{~m}$ from the interaction, and the exact distance depends on the expected neutron fluxes and the detection efficiency of the detector.

Clear separation between the two signals is then achieved by attenuating the gamma signal by adding shielding material in front of the scintillator in the line of sight to the neutron source. Lead $(\mathrm{Pb})$ is a standard choice of shielding material due to its high attenuation of gamma radiation. As an example, the mass attenuation coefficients for $\mathrm{X}$-rays in lead and in polyethylene (a standard neutron shielding material) are plotted as a function of photon energy in Figure 7a. Due to the higher density of lead compared 
to polyethylene, the attenuation coefficients differ by up to three orders of magnitude depending on the X-ray energy. To achieve a clear separation such as the one shown in Figure 6, the thickness of the lead shielding is adjusted between approximately $5-30 \mathrm{~cm}$.

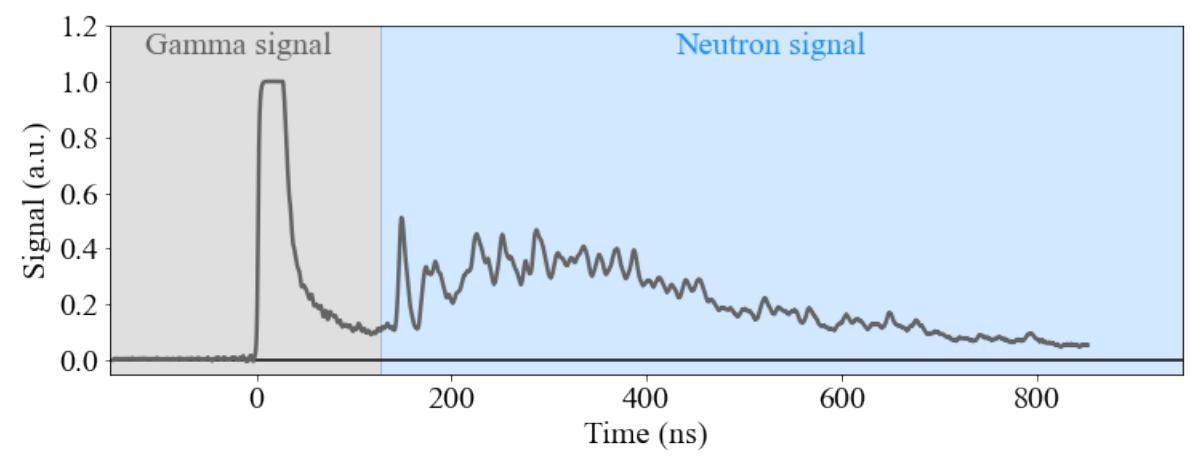

Figure 6. The raw nTOF detector trace recorded for a pitcher-catcher configuration located $7.2 \mathrm{~m}$ away with $27 \mathrm{~cm}$ lead shielding in front of the nTOF shows a gamma peak component followed by the neutron signal.

(a)

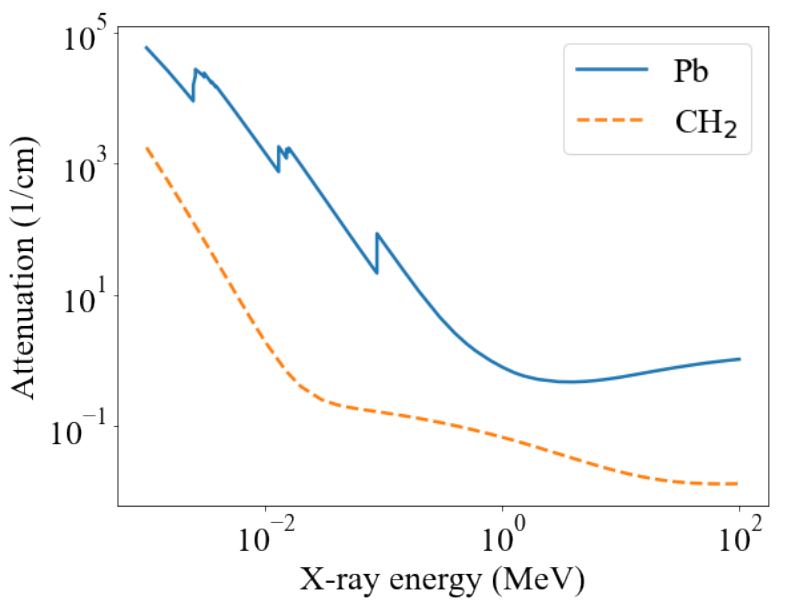

(b)

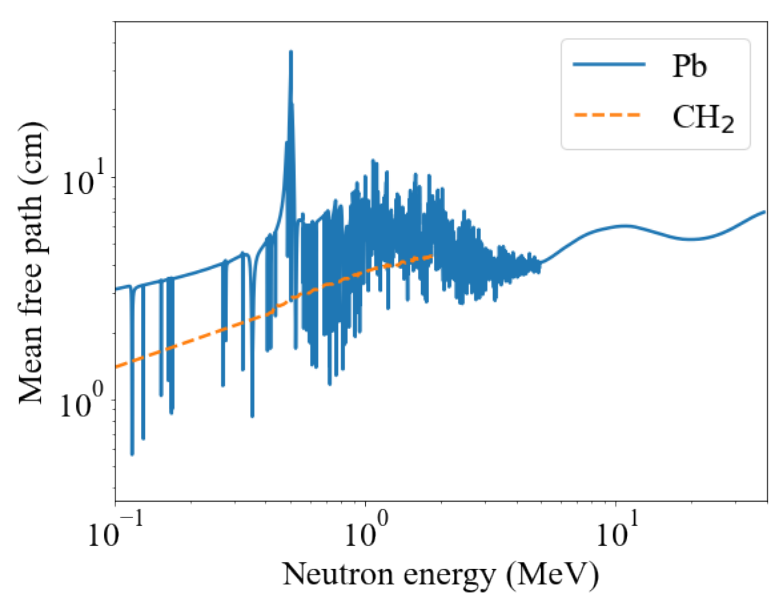

Figure 7. (a): X-ray attenuation coefficient $(1 / \mathrm{cm})$ shows superior $x$-ray attenuation up to three orders of magnitude in lead $(\mathrm{Pb})$ over polyethylene $\left(\mathrm{CH}_{2}\right)$ [104]; (b): Neutron mean free path in lead and polyethylene $[79,81,105,106]$.

Additional neutron shielding, made of $5 \mathrm{~cm}$ thick high-density polyethylene (HDPE), modeled as $\mathrm{CH}_{2}$, is added to the sides and part of the front of the detector, leaving a circular hole in the shielding of the same diameter as the scintillator. HDPE has a low mean free path for neutrons, see Figure $7 \mathrm{~b}$, effectively preventing scattered, lower-energy neutrons from being detected in the scintillator and ensuring that only neutrons on a direct flight path from the neutron source to the detector are measured. To estimate the shielding thickness necessary to block these scattered neutrons, one needs to consider two different parameters, the mean free path of neutrons in the shielding material, as shown in Figure $7 \mathrm{~b}$, and the number of collisions necessary to reduce the energy of the incident neutron to a specific value. The main difference in shielding thickness is determined by the number of collisions $n$ given by

$$
n=\log \frac{E_{n}}{E_{0}} / \log \frac{A^{2}+1}{(A+1)^{2}}
$$

where $E_{n}$ is the final neutron energy, given by the drop in detection sensitivity of the nTOF detector at $\sim 1 \mathrm{MeV}, E_{0}$ is the initial neutron energy, and $A$ is the atomic mass number [107]. 
Considering a neutron with $5 \mathrm{MeV}$ initial energy, the number of necessary collisions to downscatter the neutron to a final energy of $1 \mathrm{MeV}$ for the different materials are:

$$
n_{H}=3, \quad n_{C}=11, \quad n_{C_{2}}=\frac{1}{3} n_{C}+\frac{2}{3} n_{H} \approx 6, \quad n_{P b}=169 .
$$

The combination of a similar mean free path of neutrons in lead and polyethylene and the calculated necessary numbers of collision yield a larger shielding thickness for lead making polyethylene is a superior neutron-shielding material. It is important to note that this calculation is only an estimate of the shielding thickness; for more precise values, it would be necessary to take into account diffusion in the material and the energy loss of the neutron along its path.

Since nTOF detectors are initially not calibrated, the relation between the measured signal (e.g., Volts) and the incident neutron numbers on the detector as a function of energy is unknown. For low incident neutron fluxes, the detector can be operated in counting mode. Here, individual peaks can be detected with the signal height and timing being preserved so that single neutrons can be resolved. Therefore, the total number of neutrons incident on the detector as well as the signal per incident neutron can be determined, taking into account the detection efficiency of the scintillator. While the counting mode is preferred for its high single-neutron detection efficiency, this detection mode cannot be sustained during laser-driven neutron generation due to the significantly higher incident neutron flux where multiple neutrons are detected at once, referred to as Campbelling or mean square voltage (MSV) mode. In this mode, both the signal mean and variance are proportional to the event rate [108,109]. Consequently, the response of the detector becomes nonlinear and is not directly proportional to the incident neutron flux. It is therefore necessary to calibrate the response of the detector to neutrons, preferably in an environment similar to the high-radiation environment present during laser-matter interactions. It can be conducted offline at a neutron source with a well-characterized spectrum such as LANSCE $\left(0.1-400 \mathrm{MeV}\right.$, up to $\left.0.1 \frac{\mathrm{n}}{\mathrm{cm}^{2} \mathrm{MeV} \mathrm{s}}\right)$ [110]. Such a measurement additionally enables the identification of gain settings and neutron fluxes at which the signal of the scintillator/PMT assembly becomes independent of the incident neutron flux (i.e., saturation limits).

\section{Single-Shot Demonstration}

As a proof-of-principle experiment, the presented platform was implemented at the Texas Petawatt (TPW) Laser facility. The laser pulse was focused onto the cryogenic jet target using an $\mathrm{f} / 3$ final focusing optic with a focal spot of $5 \mu \mathrm{m}$, containing $50 \%$ of the laser energy and reaching energies on target of up to $135 \mathrm{~J}\left(\sim 10^{20}-10^{21} \mathrm{~W} / \mathrm{cm}^{2}\right)$ with a pulse duration of $135 \mathrm{fs}$ and a shot rate of 1 shot/hour. In the following, we present exemplary data obtained with the described setup utilizing single-shot diagnostics, such as image plates and bubble detectors.

In a first step, the deuteron yield was optimized in terms of target parameters to obtain maximum deuteron flux and energies in the target normal direction. After implementation of the converter in the target normal direction, the deuteron spectrum was continuously monitored using the Thomson parabola implemented at $30^{\circ}$ from target normal; see an example spectrum in Figure 8. The raw data from the image plate scan is shown in (a), where brightness is proportional to incident flux with the integrated deuteron trace as a function of energy in (b). The spectrum shows deuteron energies of up to $35 \mathrm{MeV}$ at $30^{\circ}$ and increasing flux towards lower deuteron energies. According to TNSA-like emission of ions from the target backside, peak energies decrease as a function of the angle from the target normal. It is therefore expected that the maximum energy of deuterons incident on the converter exceeded $35 \mathrm{MeV}$. Similarly, the deuteron flux in the target normal direction is also expected to be equivalent to or greater than the flux measured at $30^{\circ}$. 
(a)

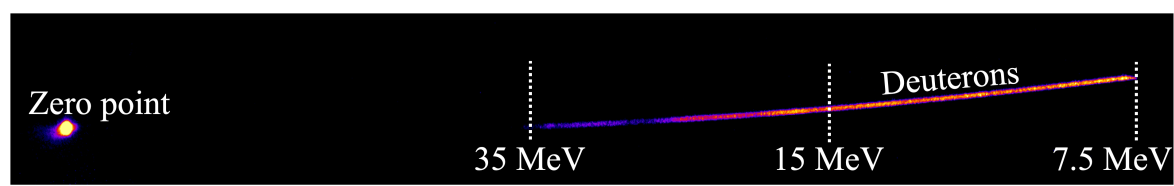

(b)

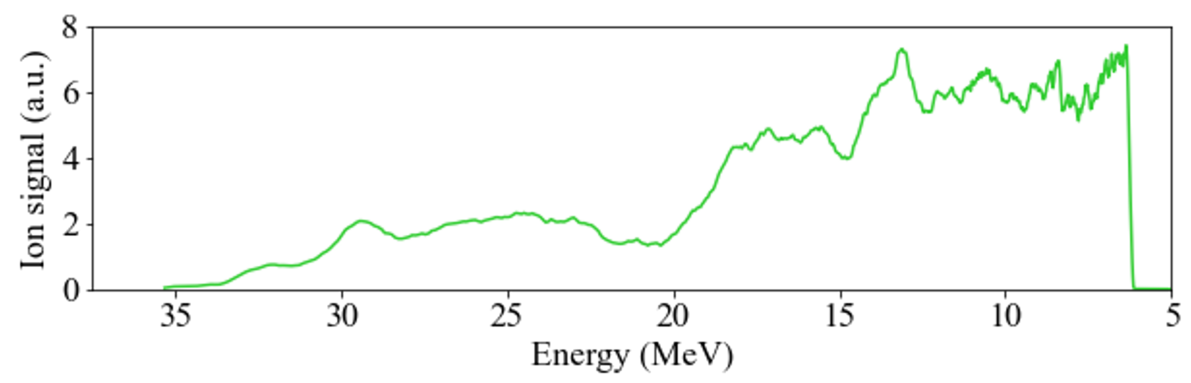

Figure 8. (a) Exemplary raw Thomson parabola trace of accelerated deuteron ion beam at $30^{\circ}$ from target normal with integrated signal as a function of deuteron energy (b).

The thickness of the beryllium layer of the converter was adjusted based on the maximum deuteron energy measured in the target normal direction to ensure that all incident deuterons were stopped in the converter. To track the deuteron beam within the converter, RCF layers, Gafchromic MD (260 $\mu \mathrm{m}$ thick), and EBT ( $278 \mu \mathrm{m}$ thick) films were added to the converter stack at different depths. The deposited ion dose on the RCF layer in the converter is shown in Figure 9a. Its position within the converter stack corresponds to a deuteron energy of $6.4 \mathrm{MeV}$. Counts were converted into dose using the calibration from Ref. [64], and the deposited dose values normalized to the maximal detected dose are indicated by the color axis. The beam offset was identified to be $\sim 10^{\circ}$ based on the radial symmetry of the deuteron beam edge as observed on the RCF. Assuming a TNSA-like profile, approximately $67 \%$ of the ion beam accelerated from the primary target is captured by the converter.

(a)

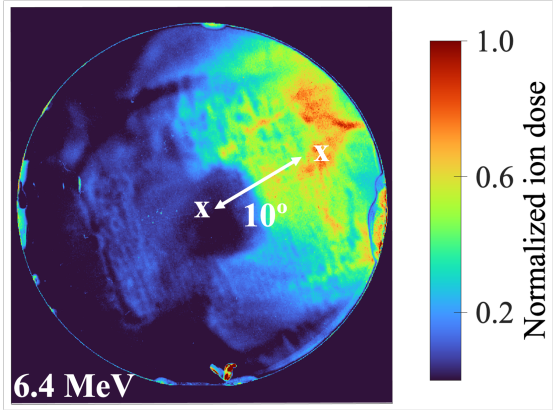

(b)

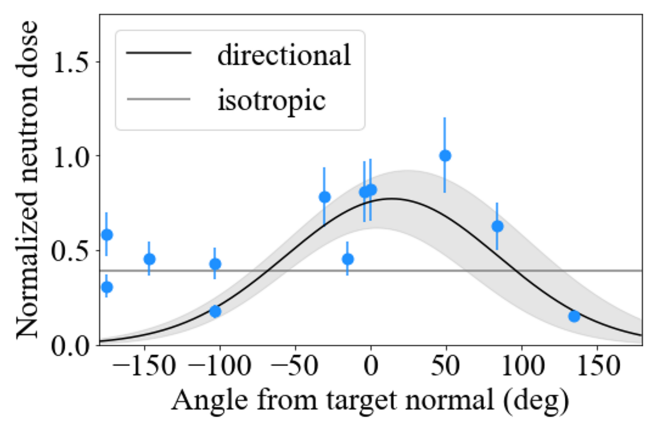

Figure 9. (a) Deuteron signal on first RCF layer within the converter at a depth equivalent to $6.4 \mathrm{MeV}$. (b) Neutron signal shown in bubble detector map in laser plane with two curves for the directional and isotropic neutron emission components to guide the eye.

Bubble detectors mounted in the laser plane characterized the emission profile shown in Figure $9 \mathrm{~b}$ with the detected doses scaled to the maximum detected value. Errors for the individual data points are determined by the measurement uncertainty of the bubble detectors of $20 \%$ of the detected dose [100]. The data shows a forward-directed neutron beam component superimposed on a quasi-isotropic neutron emission component. This is identified using two fits, light grey and black. The light grey line for the isotropic emission was obtained by averaging over data points with an angle above $100^{\circ}$. Points below $150^{\circ}$ were fitted using a gaussian curve (black) weighted by the error of the data points with the $1 \sigma$ of the fit shown as the grey shaded area. The gaussian fit to the data shows a shifted forward-directed neutron beam with its peak at $(14 \pm 10)^{\circ}$. This agrees, within the 
uncertainty, with the offset of the deuteron beam observed on the RCF. The asymmetry of the measured spatial distribution, with lower counts towards negative angles, can be explained by part of the ion beam missing the converter, which is consistent with the ion-beam imprint on the RCF.

This first proof-of-principle experiment using the presented platform was able to demonstrate high control over deuteron beam pointing through optimized jet operation, resulting in efficient, directional neutron generation in target normal direction through deuteron break-up or stripping. Paired with the previous demonstration of efficient ion generation using cryogenic jets at high repetition rates [53,59], future experiments at highrepetition-rate laser facilities will be able to study neutron generation with a focus on the effect of varying target and converter parameters on the neutron beam parameters.

\section{Discussion and Outlook}

We present a platform for high-repetition-rate laser-driven neutron generation utilizing novel technologies such as a continuous cryogenic jet target. Ion acceleration from the cryogenic jet target has already been successfully demonstrated at high repetition rates. Herein we present the full neutron generation platform in a first proof-of-principle study using the single-shot Texas Petawatt Laser facility. The setup is adaptable for different laser systems and experimental environments. It includes a suite of detectors that fully characterize the laser-driven deuteron and neutron beams and will allow the scaling of such experiments to high repetition rates. The flexibility of this setup is achieved through the design of the neutron converter in a stacked configuration. Contrary to most converters implemented during experiments so far, the length of the developed converter can be adjusted by removing or adding beryllium disks to the back of the converter depending on measured ion beam parameters. A guideline for the necessary thickness is provided by the ion beam monitoring layers that are part of the converter setup, which allow tracking of the ion beam within the converter and precise adjustments of the placement of the converter or the pointing of the ion beam. Combining lithium and beryllium in the converter allows the neutron yield to be maximized for a given energy spectrum of the incident deuteron beam.

The neutron emission profile and energy distribution at different angles provides insights into the dominant neutron production channels, which will enable understanding of the processes of neutron generation within the converter. For this, a variety of ion beam diagnostics allows the ion beam to be characterized in detail initially and then monitored throughout the experiment in order to predict neutron yields using simulations, which can in turn be compared with experimental results. Neutron beam diagnostics enable the identification of the primary neutron source and characterization of the neutron emission profile and energy distribution. The primary neutron source is determined using the angular and $r^{2}$ setup utilizing a set of bubble detectors.

Successful first proof-of-principle measurements on a single-shot basis now enable adaptation of the platform to high-repetition-rate operations using compatible detectors discussed in previous sections that have been developed and demonstrated or are under active investigation. Inspiration for new, suitable detectors can be drawn from neutron detectors utilized at the National Ignition Facility (NIF) [111]. Imaging techniques such as penumberal imaging, previously demonstrated for source size imaging [112], or time of flight detectors using different types of scintillators (e.g., liquid scintillators), or different detection mechanisms such as Cherenkov detectors, will significantly broaden the capabilities of this setup.

In the future, this versatile experimental platform will enable the detailed study of correlations between ion and neutron beam parameters and the dominant neutron-production mechanisms, in addition to allowing for facility-specific adjustments. Step-wise scaling of the operation of this platform to a high repetition rate will be enabled through consecutive experiments at current Ti:sapphire-based high-power laser facility with increasing repetition rates such as Gemini (RAL, UK, 1 shot/30 min) [113], Apollon (CNRS, France, $1 \mathrm{shot} / \mathrm{min}$ ) [114,115], or VEGA-2 (CLPU, Spain, 1 shot/s) [116]. By scaling the operation 
of this platform to one shot every minute or even second, the average neutron flux given in Table 1 can be increased by two to four orders of magnitude, which is comparable to the performance of spallation sources. A further increase in neutron flux can be achieved by implementing the platform at Nd:glass-based high-repetition-rate PW laser systems utilizing advanced cooling systems to allow for high-repetition-rate operation, such as the L4 beamline at ELI in the Czech Republic or the planned Matter in Extreme Conditions Upgrade (MEC-U) project at SLAC. Future high-repetition-rate neutron-generation studies at these and other facilities will give us the opportunity to determine the effects that different laser systems and environments have on neutron production mechanisms. Additionally, this platform allows for implementation of active feedback loops that will pave the road for machine-learning-driven optimization of laser-driven neutron beams based on real-time ion and neutron beam data analysis. An optimized neutron source utilizing this particular setup will enable unique pump-probe capabilities when co-located with an X-ray source, such as the planned upgrade to the MEC instrument at the Linac Coherent Light Source (LCLS) [117]. Additions to the setup, such as collimation of the forward-directed neutron beam, will enable measurements comparable to what is currently possible at standard neutron sources. At the same time, X-ray probing will allow for complimentary measurements such as fusion material studies, which are of high significance for future fusion reactor designs.

Author Contributions: Conceptualization, F.T., C.B.C. and M.G.; target operation, C.S.; investigation, F.T., C.B.C., T.D., G.D.G., H.J.Q., M.R., C.S., M.Z., S.H.G. and M.G.; writing-original draft preparation, F.T.; writing-review and editing, F.T., C.B.C., T.D., G.D.G., H.J.Q., M.R., C.S., M.Z., S.H.G. and M.G.; supervision, S.H.G. and M.G. All authors have read and agreed to the published version of the manuscript.

Funding: This research was funded by the U.S. DOE Office of Science, Fusion Energy Sciences under FWP No. 100182, and in part by the National Science Foundation under Grant No. 1632708. This experiment was supported by DOE Office of Science, Fusion Energy Sciences under Contract No. DE-SC0019167, the LaserNetUS initiative at the Texas Petawatt Laser facility. F.T. was supported by the National Nuclear Security Administration (NNSA) and by the German Academic Scholarship Foundation. C.B.C. acknowledges partial support from the Natural Sciences and Engineering Research Council of Canada (NSERC). G.D.G. acknowledges support from the DOE NNSA SSGF program under DE-NA0003960. M.R. and M.Z. were supported by the Hessian Ministry for Science and the Arts (HMWK) through the LOEWE Research Cluster Nuclear Photonics.

Institutional Review Board Statement: Not applicable.

Informed Consent Statement: Not applicable.

Data Availability Statement: The data that support the findings of this study are available from the corresponding author upon reasonable request.

Conflicts of Interest: The authors declare no conflict of interest.

\section{References}

1. Perkins, L.J.; Logan, B.G.; Rosen, M.D.; Perry, M.D.; Diaz de la Rubia, T.; Ghoniem, N.M.; Ditmire, T.; Springer, P.T.; Wilks, S.C. The investigation of high intensity laser driven micro neutron sources for fusion materials research at high fluence. Nucl. Fusion 2000, 40, 1. [CrossRef]

2. Higginson, D. P.; McNaney, J. M.; Swift, D. C.; Bartal, T.; Hey, D. S.; Kodama, R.; Le Pape, S.; Mackinnon, A.; Mariscal, D.; Nakamura, H.; et al. Laser generated neutron source for neutron resonance spectroscopy. Phys. Plasmas 2010, $17,100701$. [CrossRef]

3. Noguere, G.; Cserpak, F.; Ingelbrecht, C.; Plompen, A.J.M.; Quetel, C.R.; Schillebeeckx, P. Non-destructive analysis of materials by neutron resonance transmission. Nucl. Instrum. Methods Phys. Res. Sect. A 2007, 575, 476. [CrossRef]

4. Brown, D.R.; Gozani, T.; Loveman, R.; Bendahan, J.; Ryge, P.; Stevenson, J.; Liu, F.; Sivakumar, M. Application of pulsed fast neutrons analysis to cargo inspection. Nucl. Instrum. Methods Phys. Res. Sect. A 1994, 353, 684. [CrossRef]

5. Gray, L.; Read, J. Treatment of cancer by fast neutrons. Nature 1943, 152, 53. [CrossRef]

6. Melnichenko, Y.B.; Wignall, G.D. Small-angle neutron scattering in materials science: Recent practical applications. J. Appl. Phys. 2007, 102. [CrossRef] 
7. Chen, S.N.; Negoita, F.; Spohr, K.; d'Humières, E.; Pomerantz, I.; Fuchs, J. Extreme brightness laser-based neutron pulses as a pathway for investigating nucleosynthesis in the laboratory. Matter Radiat. Extrem. 2019, 4, 054402. [CrossRef]

8. Rebut, P.-H. ITER: The first experimental fusion reactor. Fusion Eng. Des. 1995, 30, 85-118. [CrossRef]

9. Ikeda, K. ITER on the road to fusion energy. Nucl. Fusion 2009, 50, 014002. [CrossRef]

10. Ciattaglia, S.; Federici, G.; Barucca, L.; Lampasi, A.; Minucci, S.; Moscato, I. The European DEMO fusion reactor: Design status and challenges from balance of plant point of view. In Proceedings of the 2017 IEEE International Conference on Environment and Electrical Engineering and 2017 IEEE Industrial and Commercial Power Systems Europe (EEEIC/I CPS Europe), Milan, Italy, 6-9 June 2017; pp. 1-6. [CrossRef]

11. Reinders, L.J. Post-ITER: DEMO and Fusion Power Plants. In The Fairy Tale of Nuclear Fusion; Springer International Publishing: Cham, Switzerland, 2021; pp. 455-484. [CrossRef]

12. Fusion Energy Science Advisory Committee (FESAC). Powering the Future: Fusion and Plasmas. 2020. Available online: https:/ /science.osti.gov/-/media/fes/fesac/pdf/2020/202012/DRAFT_Fusion_and_Plasmas_Report_120420.pdf (accessed on 9 September 2021).

13. Russell, G.J.; Gilmore, J.S.; Robinson, H.; Legate, G.L.; Bridge, A.; Sanchez, R.J.; Brewton, R.J.; Woods, R.; Hughes, H.G. LANSCE target system performance. In Advanced Neutron Sources; IOP Publishing Ltd: Bristol, UK, 1988; pp. 483-496.

14. International Atomic Energy Agency (IAEA). Research Reactor Details-LENA, TRIGA II PAVIA. 2009. Available online: http:/ / www-naweb.iaea.org/napc/physics/research_reactors/database/RR\%20Data\%20Base/datasets/report/Italy\%20 (Italian\%20Republic)\%20\%20Research\%20Reactor\%20Details\%20-\%20LENA,\%20TRIGA\%20II\%20PAVIA.htm (accessed on 8 October 2021).

15. Comsan, M.N.H. Spallation Neutron Sources for Science and Technology. 2011. Available online: http://www.iaea.org/inis/ collection/NCLCollectionStore/_Public/43/099/43099436.pdf (accessed on 8 October 2021).

16. Roth, M.; Jung, D.; Falk, K.; Guler, N.; Deppert, O.; Devlin, M.; Favalli, A.; Fernandez, J.; Gautier, D.; Geissel, M.; et al. Bright Laser-Driven Neutron Source Based on the Relativistic Transparency of Solids. Phys. Rev. Lett. 2013, 110, 044802. [CrossRef]

17. Pomerantz, I.; McCary, E.; Meadows, A.R.; Arefiev, A.; Bernstein, A.C.; Chester, C.; Cortez, J.; Donovan, M.E.; Dyer, G.; Gaul, E.W.; et al. Ultrashort Pulsed Neutron Source. Phys. Rev. Lett. 2014, 113, 184801. [CrossRef]

18. Higginson, D.P.; Vassura, L.; Gugiu, M.M.; Antici, P., Borghesi, M.; Brauckmann, S.; Diouf, C.; Green, A.; Palumbo, L.; Petrascu, H.; et al. Temporal Narrowing of Neutrons Produced by High-Intensity Short-Pulse Lasers. Phys. Rev. Lett. 2015, 115, 054802. [CrossRef]

19. Herrmann, M.C. (Lawrence Livermore National Laboratory, P. O. Box 808, Livermore, CA 94551), Personal Communication, 2021.

20. Kodama, R.; Norreys, P.A.; Mima, K.; Dangor, A.E.; Evans, R.G.; Fujita, H.; Kitagawa, Y.; Krushelnick, K.; Miyakoshi, T.; Miyanaga, N.; et al. Fast heating of ultrahigh-density plasma as a step towards laser fusion ignition. Nature 2001, 412, 798-802. [CrossRef] [PubMed]

21. Betti, R. and Hurricane, O. Inertial-confinement fusion with lasers. Nat. Phys. 2016, 12, 435-448. [CrossRef]

22. Radha, P.B.; Betti, R.; Boehly, T.R.; Delettrez, J.A.; Edgell, D.H.; Goncharov, V.N.; Igumenshchev, I.V.; Knauer, J.P.; Marozas, J.A.; Marshall, F.J.; et al. Inertial Confinement Fusion Using the OMEGA Laser System. IEEE Trans. Plasma Sci. 2011, 39, 1007-1014. [CrossRef]

23. Glenzer, S.H.; MacGowan, B.J.; Michel, P.; Meezan, N.B.; Suter, L.J.; Dixit, S.N.; Kline, J.L.; Kyrala, G.A.; Bradley, D.K.; Callahan, D.A.; et al. Symmetric Inertial Confinement Fusion Implosions at Ultra-High Laser Energies. Science 2010, 327, $1228-1231$. [CrossRef]

24. Disdier, L.; Garçonnet, J.-P.; Malka, G.; Miquel, J.-L. Fast Neutron Emission from a High-Energy Ion Beam Produced by a High-Intensity Subpicosecond Laser Pulse. Phys. Rev. Lett. 1999, 82, 1454-1457. [CrossRef]

25. Ditmire, T.; Zweiback, J.; Yanovsky, V.P.; Cowan, T.E.; Hays, G.; Wharton, K.B. Nuclear fusion from explosions of femtosecond laser-heated deuterium clusters. Nature 1999, 398, 6727. [CrossRef]

26. Hilscher, D.; Berndt, O.; Enke, M.; Jahnke, U.; Nickles, P.V.; Ruhl, H.; Sandner, W. Neutron energy spectra from the laser-induced $\mathrm{D}(\mathrm{d}, \mathrm{n})^{3}$ He reaction. Phys. Rev. E 2001, 64, 016414. [CrossRef]

27. Youssef, A.; Kodama, R.; Habara, H.; Tanaka, K.A.; Sentoku, Y.; Tampo, M.; Toyama, Y. Broad-range neutron spectra identification in ultraintense laser interactions with carbon-deuterated plasma. Phys. Plasmas 2005, 12, 110703. [CrossRef]

28. Lancaster, K.L.; Karsch, S.; Habara, H.; Beg, F.N.; Clark, E.L.; Freeman, R.; Key, M.H.; King, J.A.; Kodama, R.; Krushelnick, K.; et al. Characterization of $7 \mathrm{Li}(\mathrm{p}, \mathrm{n}) 7 \mathrm{Be}$ neutron yields from laser produced ion beams for fast neutron radiography. Phys. Plasmas 2004, 11, 3404-3408. [CrossRef]

29. Willingale, L.; Petrov, G.M.; Maksimchuk, A.; Davis, J.; Freeman, R.R.; Joglekar, A.S.; Matsuoka, T.; Murphy, C.D.; Ovchinnikov, V.M.; Thomas, A.G.R.; et al. Comparison of bulk and pitcher-catcher targets for laser-driven neutron production. Phys. Plasmas 2011, 18, 083106. [CrossRef]

30. Favalli, A.; Guler, N.; Henzlova, D.; Croft, S.; Falk, K.; Gautier, D.C.; Ianakiev, K.D.; Iliev, M.; Palaniyappan, S.; Roth, M.; et al. Characterizing laser-plasma ion accelerators driving an intense neutron beam via nuclear signatures. Sci. Rep. 2019, 9, 1-9. [CrossRef] [PubMed]

31. Spinka, T.M.; Haefner, C. High Average-Power Ultrafast Lasers. In Optics \& Photonics News; Optica: Washington, DC, USA, 2017. 
32. Nakamura, K.; Mao, H.-S.; Gonsalves, A.J.; Vincenti, H.; Mittelberger, D.E.; Daniels, J.; Magana, A.; Toth, C.; Leemans, W.P. Diagnostics, Control and Performance Parameters for the BELLA High Repetition Rate Petawatt Class Laser. IEEE J. Quantum Electron. 2017, 53, 1-21. [CrossRef]

33. Bayramian, A.; Bopp, R.; Borden, M.; Deri, B.; DesJardin, R.; Di Nicola, J.M.; Drouin, M.; Erlandson, A.; Fulkerson, S.; Jarboe, J.; et al. High energy, high average power, DPSSL system for next generation petawatt laser systems. In Proceedings of the 2016 Conference on Lasers and Electro-Optics, CLEO 2016, San Jose, CA, USA, 5-10 June 2016; pp. 3-4. [CrossRef]

34. Curry, C.B.; Schoenwaelder, C.; Goede, S.; Kim, J.B.; Rehwald, M.; Treffert, F.; Zeil, K.; Glenzer, S.H.; Gauthier, M. Cryogenic Liquid Jets for High Repetition Rate Discovery Science. J. Vis. Exp. 2020, 159, e61130. [CrossRef] [PubMed]

35. Fuchs, J.; Antici, P.; d'Humières, E.; Lefebvre, E.; Borghesi, M.; Brambrink, E.; Cecchetti, C.A.; Kaluza, M.; Malka, V.; Manclossi, M.; et al. Laser-driven proton scaling laws and new paths towards energy increase. Nat. Phys. 2005, 2, 48-54. [CrossRef]

36. Zeil, K.; Kraft, S.D.; Bock, S.; Bussmann, M.; Cowan, T.E.; Kluge, T.; Metzkes, J.; Richter, T.; Sauerbrey, R.; Schramm, U. The scaling of proton energies in ultrashort pulse laser plasma acceleration. New J. Phys. 2010, 12. [CrossRef]

37. Brenner, C.M.; Green, J.S.; Robinson, A.P.L.; Carroll, D.C.; Dromey, B.; Foster, P.S.; Kar, S.; Li, Y.T.; Markey, K.; Spindloe, C.; et al. Dependence of laser accelerated protons on laser energy following the interaction of defocused, intense laser pulses with ultra-thin targets. Laser Part. Beams 2011, 29, 345-351. [CrossRef]

38. Simpson, R.A.; Scott, G.G.; Mariscal, D.; Rusby, D.; King, P.M.; Grace, E.; Aghedo, A.; Pagano, I.; Sinclair, M.; Armstrong, C.; et al. Scaling of laser-driven electron and proton acceleration as a function of laser pulse duration, energy, and intensity in the multi-picosecond regime. Phys. Plasmas 2021, 28, 013108. [CrossRef]

39. Higginson, D.P.; McNaney, J.M.; Swift, D.C.; Petrov, G.M.; Davis, J.; Frenje, J.A.; Jarrott, L.C.; Kodama, R.; Lancaster, K.L.; Mackinnon, A.J.; et al. Production of neutrons up to $18 \mathrm{MeV}$ in high-intensity, short-pulse laser matter interactions. Phys. Plasmas 2011, 18, 100703. [CrossRef]

40. Jung, D.; Falk, K.; Guler, N.; Deppert, O.; Devlin, M.; Favalli, A.; Fernandez, J.C.; Gautier, D.C.; Geissel, M.; Haight, R.; et al. Characterization of a novel, short pulse laser-driven neutron source. Phys. Plasmas 2013, 20, 056706. [CrossRef]

41. Zulick, C.; Dollar, F.; Chvykov, V.; Davis, J.; Kalinchenko, G.; Maksimchuk, A.; Petrov, G.M.; Raymond, A.; Thomas, A.G.R.; Willingale, L.; et al. Energetic neutron beams generated from femtosecond laser plasma interactions. Appl. Phys. Lett. 2013, 102, 124101. [CrossRef]

42. Kar, S.; Green, A.; Ahmed, H.; Alejo, A.; Robinson, A.P.L.; Cerchez, M.; Clarke, R.; Doria, D.; Dorkings, S.; Fernandez, J.; et al. Beamed neutron emission driven by laser accelerated light ions. New J. Phys. 2016, 18, 053002. [CrossRef]

43. Alejo, A.; Krygier, A.G.; Ahmed, H.; Morrison, J.T.; Clarke, R.J.; Fuchs, J.; Green, A.; Green, J.S.; Jung, D.; Kleinschmidt, A.; et al. High flux, beamed neutron sources employing deuteron-rich ion beams from $\mathrm{D}_{2} \mathrm{O}$-ice layered targets. Plasma Phys. Control. Fusion 2017, 59, 064004. [CrossRef]

44. Kim, J. B.; Goede, S.; Glenzer, S.H. Development of a cryogenic hydrogen microjet for high-intensity, high-repetition rate experiments. Rev. Sci. Inst. 2016, 87, 11. [CrossRef] [PubMed]

45. Treffert, F.; Curry, C.B.; Ditmire, T.; Galtier, E.; Glenn, G.D.; Quevedo, H.J.; Richmond, G.; Roth, M.; Schoenwaelder, C.; Zimmer, M.; et al. High flux fast neutron beams using low-Z cryogenic jet targets. 2021. In preparation

46. Neely, D.; Foster, P.; Robinson, A.; Lindau, F.; Lundh, O.; Persson, A.; Wahlström, C.-G.; McKenna, P. Enhanced proton beams from ultrathin targets driven by high contrast laser pulses. Appl. Phys. Lett. 2006, 89, 021502. [CrossRef]

47. Antici, P.; Fuchs, J.; d’Humières, E.; Lefebvre, E.; Borghesi, M.; Brambrink, E.; Cecchetti, C.A.; Gaillard, S.; Romagnani, L.; Sentoku, Y.; et al. Energetic protons generated by ultrahigh contrast laser pulses interacting with ultrathin targets. Phys. Plasmas 2007, 14, 030701. [CrossRef]

48. Ceccotti, T.; Lévy, A.; Popescu, H.; Réau, F.; D’Oliveira, P.; Monot, P.; Geindre, J.P.; Lefebvre, E.; Martin, P. Proton Acceleration with High-Intensity Ultrahigh-Contrast Laser Pulses. Phys. Rev. Lett. 2007, 99, 185002. [CrossRef] [PubMed]

49. Cunningham, E.; Galtier, E.; Dyer, G.; Robinson, J.; Fry, A. Pulse contrast enhancement via non-collinear sum-frequency generation with the signal and idler of an optical parametric amplifier. Appl. Phys. Lett. 2019, 114, 221106. [CrossRef]

50. Rödel, C.; Heyer, M.; Behmke, M.; Kübel, M.; Jäckel, O.; Ziegler, W.; Ehrt, D.; Kaluza, M.C.; Paulus, G.G. High repetition rate plasma mirror for temporal contrast enhancement of terawatt femtosecond laser pulses by three orders of magnitude. Appl. Phys. B 2011, 103, 295-302. [CrossRef]

51. Poole, P.; Krygier, A.; Cochran, G.E.; Foster, P.S.; Scott, G.G.; Wilson, L.A.; Bailey, J.; Bourgeois, N.; Hernandez-Gomez, C.; Neely, D.; et al. Experiment and simulation of novel liquid crystal plasma mirrors for high contrast, intense laser pulses. Sci. Rep. 2016, 6, 32041. [CrossRef]

52. Gauthier, M.; Kim, J.B.; Curry, C.B.; Aurand, B.; Gamboa, E.J.; Goede, S.; Goyon, C.; Hazi, A.; Kerr, S.; Pak, A.; et al. High-intensity laser-accelerated ion beam produced from cryogenic micro-jet target. Rev. Sci. Inst. 2016, 87, 11. [CrossRef] [PubMed]

53. Obst, L.; Goede, S.; Rehwald, M.; Brack, F.-E.; Branco, J.; Bock, S.; Bussmann, M.; Cowan, T.E.; Curry, C.B.; Fiuza, F.; et al. Efficient laser-driven proton acceleration from cylindrical and planar cryogenic hydrogen jets. Sci. Rep. 2017, 7. [CrossRef] [PubMed]

54. Snavely, R.A.; Key, M.H.; Hatchett, S.P.; Cowan, T.E.; Roth, M.; Phillips, T.W.; Stoyer, M.A.; Henry, E.A.; Sangster, T.C.; Singh, M.S.; et al. Intense High-Energy Proton Beams from Petawatt-Laser Irradiation of Solids. Phys. Rev. Lett. 2000, 85, $2945-2948$. [CrossRef]

55. Wilks, S.C.; Langdon, A.B.; Cowan, T.E. ; Roth, M.; Singh, M.; Hatchett, S.; Key, M.H.; Pennington, D.; MacKinnon, A.; Snavely, R.A. Energetic proton generation in ultra-intense laser-solid interactions. Phys. Plasmas 2001, 8, 542-549. [CrossRef] 
56. Mora, P. Plasma Expansion into a Vacuum. Phys. Rev. Lett. 2003, 90, 185002. [CrossRef] [PubMed]

57. Roth, M.; Schollmeier, M. Ion Acceleration-Target Normal Sheath Acceleration. In Proceedings of the 2014 CAS-CERN Accelerator School: Plasma Wake Acceleration, Geneva, Switzerland, 23-29 November 2014; Volume 1.

58. Zeil, K.; Metzkes, J.; Kluge, T.; Bussmann, M.; Cowan, T.E.; Kraft, S.D.; Sauerbrey, R.; Schmidt, B.; Zier, M.; Schramm U. Robust energy enhancement of ultrashort pulse laser accelerated protons from reduced mass targets. Plasma Phys. Control. Fusion 2014, 56, 084004. [CrossRef]

59. Gauthier, M.; Curry, C.B.; Goede, S.; Brack, F.-E.; Kim, J.B.; MacDonald, M.J.; Metzkes, J.; Obst, L.; Rehwald, M.; Rödel, C.; et al. High repetition rate, multi-MeV proton source from cryogenic hydrogen jets. Appl. Phys. Lett. 2017, 111, 114102. [CrossRef]

60. Kojima, S.; Inoue, S.; Dinh, T.H.; Hasegawa, N.; Mori, M.; Sakaki, H.; Yamamoto, Y.; Sasaki, T.; Shiokawa, K.; Kondo, K.; et al. Compact Thomson parabola spectrometer with variability of energy range and measurability of angular distribution for low-energy laser-driven accelerated ions. Rev. Sci. Instrum. 2020, 91, 053305. [CrossRef]

61. Tanaka, K.A.; Yabuuchi, T.; Sato, T.; Kodama, R.; Kitagawa, Y.; Takahashi, T.; Ikeda, T.; Honda, Y.; Okuda, S. Calibration of imaging plate for high energy electron spectrometer. Rev. Sci. Instrum. 2005, 76, 013507. [CrossRef]

62. Borghesi, M.; Schiavi, A.; Campbell, D.H.; Haines, M.G.; Willi, O.; Mackinnon, A.J.; Patel, P.; Galimberti, M.; Gizzi, L.A. Proton imaging detection of transient electromagnetic fields in laser-plasma interactions (invited). Rev. Sci. Instrum. 2003, 74, 1688-1693. [CrossRef]

63. Hey, D.S.; Key, M.H.; Mackinnon, A.J.; MacPhee, A.G.; Patel, P.K.; Freeman, R.R.; Van Woerkom, L.D.; Castaneda, C.M. Use of GafChromic film to diagnose laser generated proton beams. Rev. Sci. Instrum. 2008, 79, 053501. [CrossRef]

64. Curry, C. B.; Dunning, C.A.S.; Gauthier, M.; Chou, H.-G.J.; Fiuza, F.; Glenn, G.D.; Tsui, Y.Y.; Bazalova-Carter, M.; Glenzer, S.H. Optimization of radiochromic film stacks to diagnose high-flux laser-accelerated proton beams. Rev. Sci. Instrum. 2020, $91,093303$. [CrossRef]

65. Green, J.S.; Borghesi, M.; Brenner, C.M.; Carroll, D.C.; Dover, N.P.; Foster, P.S.; Gallegos, P.; Green, S.; Kirby, D.; Kirkby, K.J.; et al. Scintillator-based ion beam profiler for diagnosing laser-accelerated ion beams. Laser-Gener. Second. Sources Radiat. Part 2011, 8079, 807919. [CrossRef]

66. Schwind, K.M.; Aktan, E.; Prasad, R.; Cerchez, M.; Eversheim, D.; Willi, O.; Aurand, B. An online beam profiler for laseraccelerated protons. Rev. Sci. Instrum. 2019, 90. [CrossRef]

67. Huault, M.; De Luis, D.; Apiñaniz, J.I.; De Marco, M.; Salgado, C.; Gordillo, N.; Gutiérrez Neira, C.; Pérez-Hernández, J.A.; Fedosejevs, R.; Gatti, G.; et al. A 2D scintillator-based proton detector for high repetition rate experiments. High Power Laser Sci. Eng. 2019, 7, 8-13. [CrossRef]

68. Metzkes, J.; Zeil, K.; Kraft, S.D.; Karsch, L.; Sobiella, M.; Rehwald, M.; Obst, L.; Schlenvoigt, H.-P.; Schramm, U. An online, energy-resolving beam profile detector for laser-driven proton beams. Rev. Sci. Instrum. 2016, 87. [CrossRef] [PubMed]

69. Dover, N. P.; Nishiuchi, M.; Sakaki, H.; Alkhimova, M.A.; Faenov, A.Ya.; Fukuda, Y.; Kiriyama, H.; Kon, A.; Kondo, K.; Nishitani, K.; et al. Scintillator-based transverse proton beam profiler for laser-plasma ion sources. Rev. Sci. Instrum. 2017, 88. [CrossRef]

70. Hesse, M.; Ebert, T.; Zimmer, M.; Scheuren, S.; Schaumann, G.; Roth, M. Spatially resolved online particle detector using scintillators for laser-driven particle sources. Rev. Sci. Instrum. 2021, 92, 093302. [CrossRef]

71. Manuel, M.J.-E.; Tang, H.; Russell, B.K.; Willingale, L.; Maksimchuk, A.; Green, J.S.; Alfonso, E.L.; Jaquez, J.; Carlson, L.; Neely, D.; $\mathrm{Ma}, \mathrm{T}$. Enhanced spatial resolution of Eljen-204 plastic scintillators for use in rep-rated proton diagnostics. Rev. Sci. Instrum. 2020, 91, 103301. [CrossRef]

72. Avrigeanu, M.; Avrigeanu, V. Assessment of deuteron-induced reaction mechanisms at low and medium energies. In EPJ Web Conference; EDP Sciences: Les Ulis, France, 2010; Volume 2. [CrossRef]

73. Boselli, M.; Diaz-Torres, A. Unambiguous separation of low-energy fusion processes of weakly bound nuclei. J. Phys. G Nucl. Part. Phys. 2014, 41, 094001. [CrossRef]

74. Wang, H.; Otsu, H.; Chiga, N.; Kawase, S.; Takeuchi, S.; Sumikama, T.; Koyama, S.; Sakurai, H.; Watanabe, Y.; Nakayama, S.; et al. Enhancement of element production by incomplete fusion reaction with weakly bound deuteron. Commun. Phys. $2019,2,78$. [CrossRef]

75. Storm, M.; Jiang, S.; Wertepny, D.; Orban, C.; Morrison, J.; Willis, C.; McCary, E.; Belancourt, P.; Snyder, J.; Chowdhury, E.; et al. Fast neutron production from lithium converters and laser driven protons. Phys. Plasmas 2013, 20, 053106. [CrossRef]

76. Petrov, G.M.; Higginson, D.P.; Davis, J.; Petrova, Tz.B.; McGuffey, C.; Qiao, B.; Beg, F.N. Generation of energetic (>15 MeV) neutron beams from proton- and deuteron-driven nuclear reactions using short pulse lasers. Plasma Phys. Control Fusion 2013, 55, 105009. [CrossRef]

77. Ye, T.; Watanabe, Y.; Ogata, K. Analysis of deuteron breakup reactions on ${ }^{7} \mathrm{Li}$ for energies up to $100 \mathrm{MeV}$. Phys. Rev. C 2009, 80, 014604. [CrossRef]

78. Parfenova, Y.L.; Zhukov, M.V. Study of deuteron breakup in light targets at intermediate energies. Eur. Phys. J. A 2001, 12, 191-197. [CrossRef]

79. Brown, D. A.; Chadwick, M.B.; Capote, R.;Kahler, A.C.;Trkov, A.; Herman, M.W.; Sonzogni, A.A.; Danon, Y.; Carlson, A.D.; Dunn, M.; et al. ENDF/B-VIII.0: The 8th Major Release of the Nuclear Reaction Data Library with CIELO-project Cross Sections, New Standards and Thermal Scattering Data. Nucl. Data Sheets 2018, 148, 1-142. [CrossRef]

80. Koning, A. J.; Rochman, D.; Sublet, J.-Ch.; Dzysiuk, N.; Fleming, M.; van der Marck, S. TENDL: Complete Nuclear Data Library for Innovative Nuclear Science and Technology. Nucl. Data Sheets 2019, 155, 1-55. [CrossRef] 
81. Shinsuke N.; Iwamoto, O.; Watanabe, Y.; Ogata, K. JENDL/DEU-2020: Deuteron nuclear data library for design studies of accelerator-based neutron sources. J. Nucl. Sci. Technol. 2021, 58, 805-821. [CrossRef]

82. Hermanne, A.; Tarkanyi, F.; Takacs, S. Activation cross sections for production of 7Be by proton and deuteron induced reactions on 9Be: Protons up to 65MeV and deuterons up to 50MeV. Appl. Radiat. Isot. 2014, 90, 203-207. [CrossRef]

83. Generalov, L.N.; Abramovich, S.N.; Selyankina, S.M. Activation measurements of the integral cross sections of reactions 7Li(p,n0+n1)7Be(gs), 6Li(d,n0+n1)7Be(gs), 7Li(d,2n)7Be(gs), 65Cu(p,n)65Zn, 65Cu(d,2n)65Zn, 63Cu(d,g)65Zn. Bull. Russ. Acad. Sci. Phys. 2017, 81, 644-657. [CrossRef]

84. Osetinskij, G.M.; Sikora, B.; Tyke, Ya.; Fryshchin, B. The investigation of Li-7(d,n)Be-8 reaction. Jt. Inst. Nucl. Res. Dubna Rep. 1970, 5143.

85. Koning, A.J.; Rochman, D. Modern Nuclear Data Evaluation with the TALYS Code System. Nucl. Data Sheets 2012, 113, 2841-2934. [CrossRef]

86. Nelson, C.E.; Purser, F.O.; Von Behren, P.; Newson, H.W. Neutron spectra from deuteron and proton bombardment of thick lithium targets: Potential for neutron therapy. Phys. Med. Biol. 1978, 23, 39-46. [CrossRef] [PubMed]

87. Hagiwara, M.; Itoga, T.; Kawata, N.; Hirabayashi, N.; Oishi, T.; Yamauchi, T.; Baba, M.; Sugimoto, M.; Muroga, T. Measurement of Neutron Emission Spectra in $\mathrm{Li}(\mathrm{d}, \mathrm{xn})$ Reaction with Thick and Thin Targets for 40-MeV Deuterons. Fusion Sci. Technol. 2005, 48, 1320-1328. [CrossRef]

88. Ménard, S.; Mirea, M.; Clapier, F.; Pauwels, N.; Proust, J.; Donzaud, C.; Guillemaud-Mueller, D.; Lhenry, I.; Mueller, A.C.; Scarpaci, J.A.; Sorlin, O. Fast neutron forward distributions from C, Be, and U thick targets bombarded by deuterons. Phys. Rev. ST Accel. Beams 1999, 2, 033501. [CrossRef]

89. Fischer, U.; Simakov, S.P.; Konobeyev, A.; Pereslavtsev, P.; Wilson, P. Neutronics and nuclear data for the IFMIF neutron source. Fusion Eng. Des. 2002, 63-64, 493-500. [CrossRef]

90. Fischer, U.; Avrigeanu, M.; Pereslavtsev, P.; Simakov, S.P.; Schmuck, I. Evaluation and validation of d-Li cross section data for the IFMIF neutron source term simulation. J. Nucl. Mater. 2007, 367-370, 1531-1536. [CrossRef]

91. Zimmer, M. Laser Driven Neutron Sources-A Compact Approach to Non-Destructive Material Analysis. Ph.D. Thesis, Technische Universität Darmstadt, Darmstadt, Germany, 2020.

92. Ziegler, J.F.; Ziegler, M.D.; Biersack, J.P. SRIM - The stopping and range of ions in matter (2010). Nucl. Instruments Methods Phys. Res. Sect. B Beam Interact. Mater. Atoms 2010, 268, 1818-1823. [CrossRef]

93. Bolton, P.R.; Borghesi, M.; Brenner, C.; Carroll, D.C.; De Martinis, C.; Fiorini, F.; Flacco, A.; Floquet, V.; Fuchs, J.; Gallegos, P.; et al. Instrumentation for diagnostics and control of laser-accelerated proton (ion) beams. Phys. Med. 2014, 30, 255-270. [CrossRef] [PubMed]

94. Kleinschmidt, A.; Bagnoud, V.; Deppert, O.; Favalli, A.; Frydrych, S.; Hornung, J.; Jahn, D.; Schaumann, G. ; Tebartz, A.; Wagner, F.; et al. Intense, directed neutron beams from a laser-driven neutron source at PHELIX. Phys. Plasmas 2018, 25, 3-8. [CrossRef]

95. Lewis, B.J.; Smith, M.B.; Ing, H.; Andrews, H.R.; Machrafi, R.; Tomi, L.; Matthews, T.J.; Veloce, L.; Shurshakov, V.; Tchernykh, I.; et al. Review of bubble detector response characteristics and results from space. Radiat. Prot. Dosim. 2011, 150, 1-21. [CrossRef] [PubMed]

96. Ing, H.; Noulty, R.A.; McLean, T.D. Bubble detectors-A maturing technology. Radiat. Meas. 1997, 27, 1-11. [CrossRef]

97. Skripov, V.P. Metastable Liquids; J. Wiley \& Sons: Hoboken, NJ, USA, 1974; p. 128.

98. Bell, C.R.; Oberle, N.P.; Rohsenow, W.; Todreas, N.; Tso, C. Radiation-Induced Boiling in Superheated Water and Organic Liquids. Nucl. Sci. Eng. 1974, 53, 458-465. [CrossRef]

99. Rosenstock, W.; Schulze, J.; Köble, T.; Kruzinski, G.; Thesing, P.; Jaunich, G.; Kronholz, H.L. Estimation of Neutron Energy Spectra with Bubble Detectors: Potential and Limitations. Radiat. Prot. Dosim. 1995, 61, 133-136. [CrossRef]

100. Ing, H. Neutron measurements using bubble detectors-Terrestrial and space. Radiat. Meas. 2001, 33, 275-286. [CrossRef]

101. Plesset, M.S.; Zwick, S.A. The Growth of Vapor Bubbles in Superheated Liquids. J. Appl. Phys. 1954, 25, 493-500. [CrossRef]

102. Knoll, G.F. Radiation Detection and Measurement; John Wiley \& Sons: Hoboken, NJ, USA, 2000; Volume 3, p. 860.

103. Kouzes, R.T.; Lintereur, A.T.; Siciliano, E.R. Progress in alternative neutron detection to address the helium-3 shortage. Nucl. Instruments Methods Phys. Res. Sect. A Accel. Spectrometers Detect. Assoc. Equip. 2015, 784, 172-175. [CrossRef]

104. Berger, M.J.; Hubbell, J.H.; Seltzer, S.M.; Chang, J.; Coursey, J.S.; Sukumar, R.; Zucker, D.S.; Olsen, K. XCOM: Photon Cross Sections Database. In NIST Standard Reference Database 8 (XGAM); NIST: Gaitherburg, MD, USA, 2010; pp. 87-3597. [CrossRef]

105. Hongwei, Y. The N-P Scattering Cross Section from 90 Kev To 1.8 Mev. Ph.D. Thesis, University of Kentucky, Lexington, Kentucky, 2015.

106. Lee, J.; Nishiyama, J.; Hori, J.-I.; Kimura, R.; Sako, T.; Yamada, A.; Sano, T. Neutron total cross section measurements of polyethylene using time-of-flight method at KURNS-LINAC. J. Nucl. Sci. Technol. 2020, 57, 1-8. [CrossRef]

107. Rinar, P. Neutron Interaction with Matter. In Passive Nondestructive Assay of Nuclear Materials; U.S. Nuclear Regulatory Commission: Rockville, MD, USA, 1991; p. 357.

108. Campbell, N.; Francis, V. A theory of valve and circuit noise. J. Inst. Electr. Eng. Part III Radio Commun. Eng. 1946, $93,45-52$.

109. Zhong, G.Q.; Li, K.; Hu, L.Q.; Cao, H.R.; Zhou, R.J.; Lin, S.Y.; Hong, B.; Huo, Z.P.; Zhang, H.; Xiao, M.; et al. Development of a wide-range neutron flux monitoring system in EAST. J. Instrum. 2020, 15, P05011-P05011. [CrossRef]

110. Treffert, F.; Curry, C.B.; Quevedo, H.J.; Roth, M.; Schoenwaelder, C.; Zimmer, M.; Glenzer, S.H.; Gauthier, M. Absolute flux calibration of neutron time-of-flight detectors using high energy neutron beams at LANSCE. 2022, In preparation. 
111. Glebov, V.Y.; Meyerhofer, D.D.; Sangster, T.C.; Stoeckl, C.; Roberts, S.; Barrera, C.A.; Celeste, J.R.; Cerjan, C.J.; Dauffy, L.S.; Eder, D.C.; et al. Development of nuclear diagnostics for the National Ignition Facility (invited). Rev. Sci. Instrum. 2006, 77, 10E715. [CrossRef]

112. Guler, N.; Volegov, P.; Favalli, A.; Merrill, F.E.; Falk, K.; Jung, D.; Tybo, J.L.; Wilde, C.H.; Croft, S.; Danly, C.; et al. Neutron imaging with the short-pulse laser driven neutron source at the Trident laser facility. J. Appl. Phys. 2016, 120, 154901. [CrossRef]

113. Hooker, C.J.; Blake, S.; Chekhlov, O.; Clarke, R.J.; Collier, J.L.; Divall, E.J.; Ertel, K.; Foster, P.S.; Hawkes, S.J.; Holligan, P.; et al. Commissioning the Astra Gemini petawatt Ti:sapphire laser system. In Proceedings of the 2008 Conference on Lasers and Electro-Optics and 2008 Conference on Quantum Electronics and Laser Science, San Jose, CA, USA, 4-9 May 2008; pp. 1-2. [CrossRef]

114. Papadopoulos, D.N.; Zou, J.P.; Le Blanc, C.; Chériaux, G.; Georges, P.; Druon, F.; Mennerat, G.; Ramirez, P.; Martin, L.; Fréneaux, A.; et al. The Apollon 10 PW laser: Experimental and theoretical investigation of the temporal characteristics. High Power Laser Sci. Eng. 2016, 4, e34. [CrossRef]

115. Burdonov, K.; Fazzini, A.; Lelasseux, V.; Albrecht, J.; Antici, P.; Ayoul, Y.; Beluze, A.; Cavanna, D.; Ceccotti, T.; Chabanis, M.; et al. Characterization and performance of the Apollon Short-Focal-Area facility following its commissioning at 1 PW level. Matter Radiat. Extrem. 2021, 6, 064402 [CrossRef]

116. Huault, M.; Zeraouli, G.; Ajates, J.G.; Apiñaniz, J.; García, E.; Hernández, I.; Malko, S.; Méndez, C.; Perez, J.A.; Pisonero, J.D.; et al. Commissioning experiments of VEGA-2 at Centro de Láseres Pulsados (CLPU). In Frontiers in Optics 2017; Optical Society of America, Optica: Washington, DC, USA, 2017; p. FM2B.4. [CrossRef]

117. Glenzer, S.H.; Fletcher, L.B.; Galtier, E.; Nagler, B.; Alonso-Mori, R.; Barbrel, B.; Brown, S.B.; Chapman, D.A.; Chen, Z.; Curry, C.B.; et al. Matter under extreme conditions experiments at the Linac Coherent Light Source. J. Phys. B At. Mol. Opt. Phys. 2016, 49, 092001. [CrossRef] 